\title{
SURFACE AND MICROSTRUCTURAL CHARACTERIZATION OF COMMERCIAL BREEDER REACTOR CANDIDATE ALLOYS EXPOSED TO $700^{\circ} \mathrm{C}$ SODIUM
}

\section{Hanford Engineering Development Laboratory \\ R.P. Anantatmula \\ W.F. Brehm}

This report was prepared as an account of work

sponsored by the United States Government Nether the

United States nor the United States Depariment of

Energy, nor any of therr employees nor any of therr

contractors, subcontractors, or ther employees, makes

any warranty, express or imphed, or assumes any legal

liablity or responsabulity for the accuracy, comple teness

or usefulness of any information, apparatus, product or

process disclosed, of represents that its use would not

infrunge privately owned nghts

March 1979

HANFORD ENGINEERING DEVELOPMENT LABORATORY

Operated by Westinghouse Hanford Company

P.O. Box 1970 Richland, WA 99352

A Subsidiary of Westinghouse Electric Corporation

Prepared for the U.S. Department of Energy

under Contract No. EY-76-C-14-2170 


\section{DISCLAIMER}

This report was prepared as an account of work sponsored by an agency of the United States Government. Neither the United States Government nor any agency Thereof, nor any of their employees, makes any warranty, express or implied, or assumes any legal liability or responsibility for the accuracy, completeness, or usefulness of any information, apparatus, product, or process disclosed, or represents that its use would not infringe privately owned rights. Reference herein to any specific commercial product, process, or service by trade name, trademark, manufacturer, or otherwise does not necessarily constitute or imply its endorsement, recommendation, or favoring by the United States Government or any agency thereof. The views and opinions of authors expressed herein do not necessarily state or reflect those of the United States Government or any agency thereof. 


\section{DISCLAIMER}

Portions of this document may be illegible in electronic image products. Images are produced from the best available original document. 
SURFACE AND MICROSTRUCTURAL CHARACTERIZATION

OF COMMERCIAL BREEDER REACTOR CANDIDATE ALLOYS

EXPOSED TO $700^{\circ} \mathrm{C}$ SODIUM

\author{
R. P. Anantatmula \\ W. F. Brehm
}

\begin{abstract}
Sodium compatibility screening tests were performed on several commercial austenitic alloys at $700^{\circ} \mathrm{C}$ for 2000 hours for applications as breeder reactor fuel cladding. The sodium-exposed surfaces were characterized by Optical Metallography, Scanning Electron Microscopy (SEM) and Electron Probe Micro Analysis (EPMA).

Sodium exposure generally resulted in the depletion of $\mathrm{Ni}, \mathrm{Cr}$, $\mathrm{Ti}, \mathrm{Si}, \mathrm{Mn}$ and $\mathrm{Nb}$, and enrichment of Fe and Mo at the surface. The average thickness of the depleted zone was $5 \mu \mathrm{m}$.

The alloys can be divided into three groups based on corrosion rate, and each group has its own characteristic surface structure. Grain-orientation dependent striations were seen in alloys with low corrosion rates, while alloys with intermediate corrosion rates displayed micron-size nodes enriched with Fe and Mo. The high corrosion rate alloys exhibited scale-like formations on the surface with irregularly shaped holes. In addition, the data importantly point out that a ferrite layer will form at the sodium-exposed surface of these austenitic alloys after prolonged exposure.
\end{abstract}




\section{ACKNOWLEDGMENTS}

The authors express their gratitude for the technical assistance

of L. E. Chulos, R. R. Rake, and J. L. Bevan for loop operations, L. B. Priest for optical metallography, S. J. Mayhan for Scanning Electron Microscopy and W. I. Clark for Electron Probe Micro Analysis. Thanks are also due to J. J. Laidler for reviewing the manuscript. 


\section{CONTENTS}

Abstract

Page

Acknow ledgments

i ii

Figures

iv

vi

Tables

vii

I. INTRODUCTION 1

II. EXPERIMENTAL PROCEDURE 1

III. RESULTS 2

A. AISI $316 \quad 2$

B. AISI 310

C. ALLOY $330 \quad 10$

D. A-286 13

E. INCONEL $706 \quad 18$

F. NIMONIC PE16 24

G. M-813 28

H. INCONEL $718 \quad 31$

$\begin{array}{ll}\text { IV. DISCUSSION } & 35\end{array}$

V. CONCLUSIONS 40

VI. REFERENCES 41 


\section{FIGURES}

Figure

Page

1. Optical Micrograph of Sodium-exposed (2000 hours)

AISI 316.

2. SEM Photographs of As-received and Sodium-exposed AISI 316.

3. Optical Micrographs of As-received and Sodium-exposed AISI 310.

4. EPMA Profiles of Sodium-exposed (2000 hours) AISI $310 . \quad 8$

5. EPMA Profiles of Sodium-exposed (2000 hours) AISI 310.9

6. SEM Photographs of As-received and Sodium-exposed (2000 hours) AISI 310.

7. Optical Micrographs of As-received and Sodium-exposed Alloy 330.

8. EPMA Profiles of Sodium-exposed (2000 hours) Alloy $330 . \quad 14$

9. EPMA Profiles of Sodium-exposed (2000 hours) Alloy $330 . \quad 15$

10. SEM Photographs of As-received and Sodium-exposed (2000 hours) A110y 330.

11. Optical Micrograph of Sodium-exposed (2000 hours) A-286. 17

12. EPMA Profiles of Sodium-exposed (2000 hours) A-286. 19

13. EPMA Profiles of Sodium-exposed (2000 hours) A-286. 20

14. SEM Photographs of As-received and Sodium-exposed A-286. 21

15. Optical Micrograph of Sodium-exposed (2000 hours) Incone1 706.

16. SEM Photographs of As-received and Sodium-exposed Incone 706.

17. Optical Micrograph of Sodium-exposed (2000 hours) Nimonic PE16. 


\section{FIGURES (Cont'd)}

Figure

Page

18. EPMA Profiles of Sodium-exposed (2000 hours)

Nimonic PE16.

19. EPMA Profiles of Sodium-exposed (2000 hours)

Nimonic PE16.

20. SEM Photographs of As-received and Sodium-exposed

Nimonic PE16.

21. Optical Micrographs of As-received and Sodium-exposed M-813.

22. EPMA Profiles of Sodium-exposed (2000 hours) M-813. 32

23. EPMA Profiles of Sodium-exposed (2000 hours) M-813.

24. SEM Photographs of As-received and Sodium-exposed (2000 hours) M-813.

25. Optical Micrograph of Sodium-exposed (2000 hours) Inconel 718.

26. SEM Photographs of As-received and Sodium-exposed Inconel 718.

\section{TABLES}

Table

1. EPMA of Composition (wt\%) of Sodium-exposed (2000 hours) AISI 316. 
SURFACE AND MICROSTRUCTURAL CHARACTERIZATION

OF COMMERCIAL BREEDER REACTOR CANDIDATE ALLOYS

EXPOSED TO $700^{\circ} \mathrm{C}$ SODIUM (FF $129 / \mathrm{LLV}$ )

\section{INTRODUCTION}

Sodium compatibility tests of candidate breeder reactor fuel cladding alloys are performed by the Coolant Compatibility Task Group (Task Group E) of the National Cladding/Duct Materials Development Program (NCDMDP). The experimental work for Task $E$ is done at Hanford Engineering Development Laboratory (HEDL), Westinghouse Advanced Reactors Division (WARD) and Westinghouse Research and Development Center (WR\&D). The tests at HEDL and WR\&D are done at low axial temperature gradient (dT/dL) conditions, while the test loop at WARD provides high $\mathrm{dT/dL}$ conditions, prototypic of a breeder reactor core.

The experimental program began in 1975 with sodium compatibility tests of the candidate commercial alloys at $700^{\circ} \mathrm{C}$ and $1 \mathrm{ppm}$ oxygen. Tests on the same commercial alloys were performed at HEDL and WR\&D under the same experimental conditions to check the reproducibility of the data. The agreement between the two laboratories on the corrosion rate data and the surface and microstructural characterization data was excellent.

The present report summarizes the surface and microstructural characterization data on candidate commercial alloys obtained at HEDL. The metallographic evaluation of corrosion samples included optical metallography and SEM at both HEDL and WR\&D. In addition, Secondary Ion Mass Spectroscopy (SIMS) was used at WR\&D and EPMA was used at HEDL to make a thorough assessment of the sodium-induced effects.

\section{EXPERIMENTAL PROCEDURE}

The sodium compatibility experiments at HEDL were performed in Source Term Control Loop No. 4 (STCL-4), which is equipped with radiant heaters just upstream from the test section and produces a low $\mathrm{dT} / \mathrm{dL}$ of approximately $400 \mathrm{C} / \mathrm{m}$. 
The tests on commercial alloys were conducted in the isothermal region downstream from the heater section at $700^{\circ} \mathrm{C}, 1 \mathrm{ppm}$ oxygen in sodium and a sodium velocity of $6 \mathrm{~m} / \mathrm{s}$. The alloy samples were exposed to sodium for a time period of 2000 hours with intermediate shutdown after 500 hours. The commercial alloys tested were A-286, Nimonic PE16, M-813, AISI 310, Alloy 330, Inconel 706, Inconel 718 and the reference material AISI 316. The asreceived alloy samples were approximately $1 \mathrm{~cm}$ in length, $5.84 \mathrm{~mm}\left(0.23^{\prime \prime}\right)$ 0 . D. and $0.25 \mathrm{~mm}$ (10 mils) in wall thickness. The experimental procedure and data acquisition methods were discussed in detail elsewhere. (1)

The solution-hardened alloys (AISI 316, AISI 310, and Alloy 330) were received in the $20 \%$ cold-worked condition, while the precipitation strengthened alloys were solution annealed and aged to produce the optimum precipitate size and distribution. The thermo-mechanical treatments given these alloys were listed in an earlier paper. (2)

\section{RESULTS}

Alloys AISI 316, AISI 310 and Alloy 330 are solution-hardened austenitic, while the remaining alloys are strengthened by precipitates in the austenite matrix. The surface features of sodium-exposed samples are very distinct and depend on composition as well as the corrosion rate. The surface characteristics are especially influenced by the alloying element, molybdenum. The results of each alloy are discussed individually in the following sections and comparisons are made where appropriate. The results of solution-hardened austenitic alloys are discussed first, followed by the precipitation-strengthened alloys.

\section{A. AISI 316}

AISI 316 in the cold-worked condition displayed deformation bands.' Fresh samples of the reference material were exposed in each run of the commercial alloy group, and the corrosion rate went up slightly each time due to aging of the loop. 
Optical metallography of samples exposed for 2000 hours revealed no intergranular penetration (Figure 1). Carbide formation was seen throughout the samples at $700^{\circ} \mathrm{C}$. The deformation bands acted as nucleation sites for the carbide precipitates. As can be seen in Figure 1, sigma phase precipitates were observed underneath the depleted zone of the sample. The amount of sigma phase in the austenite matrix is approximately 11 vol\%, which is about the same as that reported for high $\mathrm{dT} / \mathrm{dL}$ conditions.

The sigma phase identification was made partially by EPMA of the precipitate particles. The results of EPMA are presented in Table 1. Most of the precipitate particles were large enough to obtain valid data. The data represent weight percents of the individual elements on the basis of a known standard sample of AISI 316. However, the data were not corrected for absorption or fluorescence effects. The compositions of the individual elements $\mathrm{Fe}, \mathrm{Cr}, \mathrm{Ni}$ and Mo reported in Table 1 are quite close to the corresponding compositions suggested by Weiss and Stickler ${ }^{(3)}$ for the sigma phase, within experimental error. In addition, the characteristic island appearance of the precipitate particles with a glyceregia etch also helped in positive identification of this phase. The Electron Vacancy Parameter calculations ${ }^{(4)}$ indicate a sigma-forming tendency for this material.

TABLE 1

EPMA OF COMPOSITION (Wt\%) OF SODIUM-EXPOSED (2000 hours) AISI 316

$\begin{array}{lccrrrr}\text { Area } & \frac{\mathrm{Fe}}{\mathrm{Fr}} & \frac{\mathrm{Ni}}{\mathrm{N}} & \mathrm{Mn} & \underline{\mathrm{Si}} & \frac{\text { Mo }}{6.3} \\ \text { Matrix } & 60.1 & 17.3 & 14.9 & 1.57 & .66 & 2.21 \\ \text { Precipitate } & 49.1 & 28.6 & 5.4 & 1.47 & 1.24 & 8.32 \\ \text { Sigma* } & 55.0 & 29.0 & 5.0 & & & 11.0\end{array}$

*Data from Reference 3. 


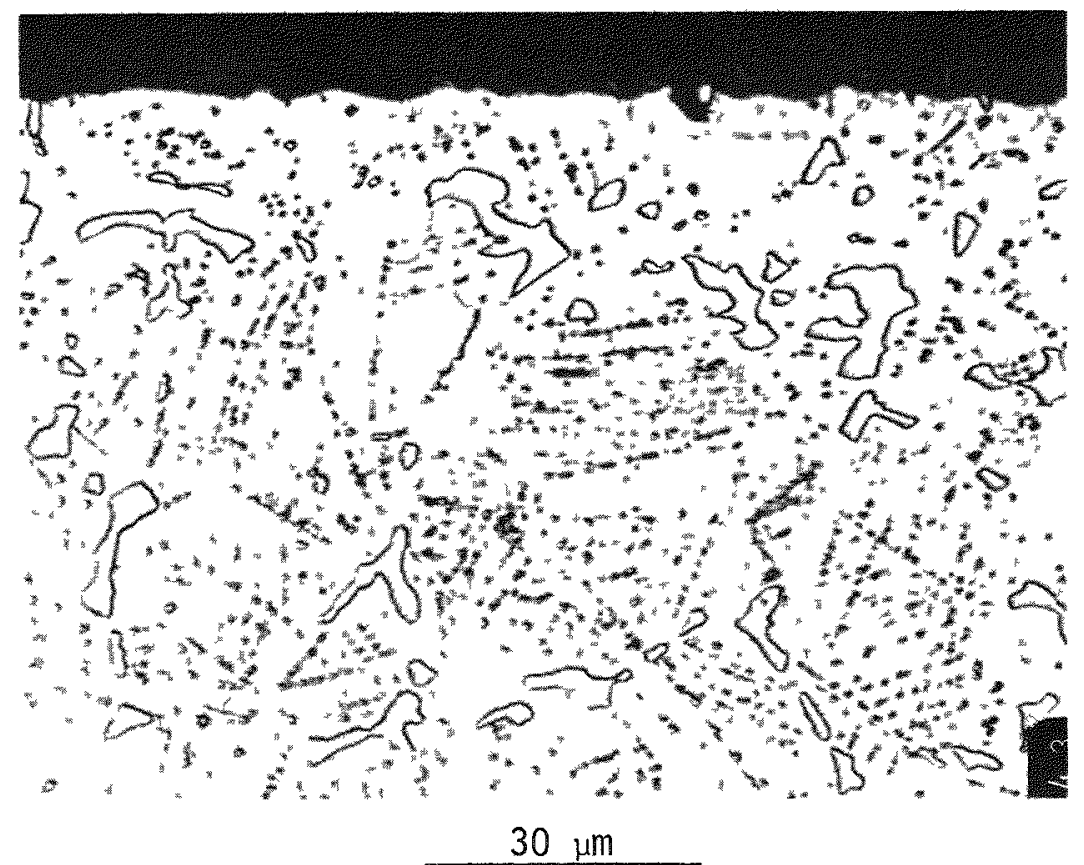

FIGURE 1. Optical Micrograph of Sodium-exposed (2000 hours) AISI 316. 
SEM data of sodium-exposed samples revealed (Figure 2) grooving of the grain boundaries due to selective grain boundary attack. Appearance of micronsize nodes may be noted on the sodium-exposed surfaces. Energy Dispersive $X$-ray Analys is of the nodes indicated enrichment with Mo, which is in agreement with previous investigations. (5) The area scan after 500 hours indicates general surface enrichment of Mo. The nodes are small and quite numerous after 500 hours. After 2000 hours, the number density of the nodes has decreased considerably and, on an average, the size has increased. This suggests that some smaller nodes are growing and others agglomerating, and a definite simultaneous undercutting of the nodes by sodium is occurring, with the eventual mechanical removal of these nodes. This is the reason for the drastic decrease in X-ray intensity of Mo in the area scan after 2000 hours.

The data seem to indicate that $\mathrm{Ni}$ and $\mathrm{Cr}$ are continuously lost from the surface and ferrite layer formation is enhanced with increase in exposure time.

\section{B. AISI 310}

The structure of as-received AISI 310 sample (Figure 3) consists of slightly distorted annealing twins and also deformation bands due to the $20 \%$ coldwork treatment given after solution anneal. The solution anneal treatment was not long enough to permit complete dissolution of carbides and a few carbides are still seen. After 2000 hours of sodium exposure, the austenite matrix underneath the depleted zone is completely covered with irregularlyshaped precipitates (Figure 3 ). The area occupied by the sigma particles is approximately $30 \%$ of the total area of the matrix. Assuming spherical particle distribution, this amounts to about 30 volume percent of sigma phase in the alloy after 2000 hours of exposure. It may be noted that the fairly large quantity of sigma is due to the low carbon level of the alloy. (6)

Composition profiles obtained from EPMA are shown in Figures 4 and 5. Depletion of $\mathrm{Ni}, \mathrm{Cr}$ and $\mathrm{Mn} \mathrm{Can}$ be seen and also extreme enrichment of $\mathrm{Fe}$ at 


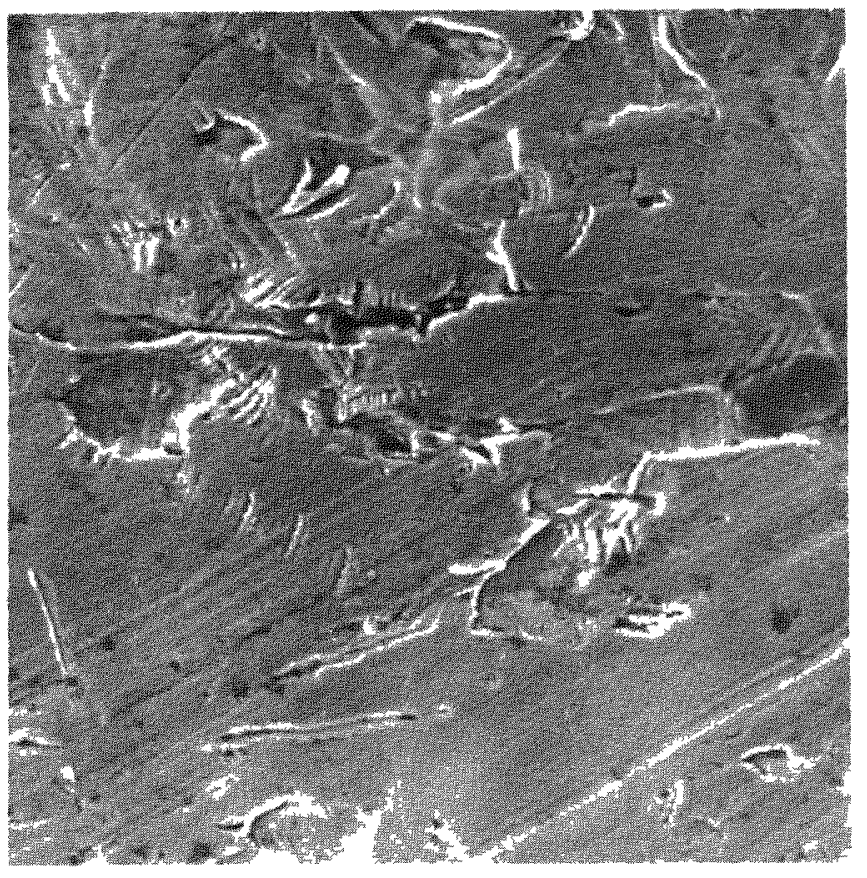

(a) As-received

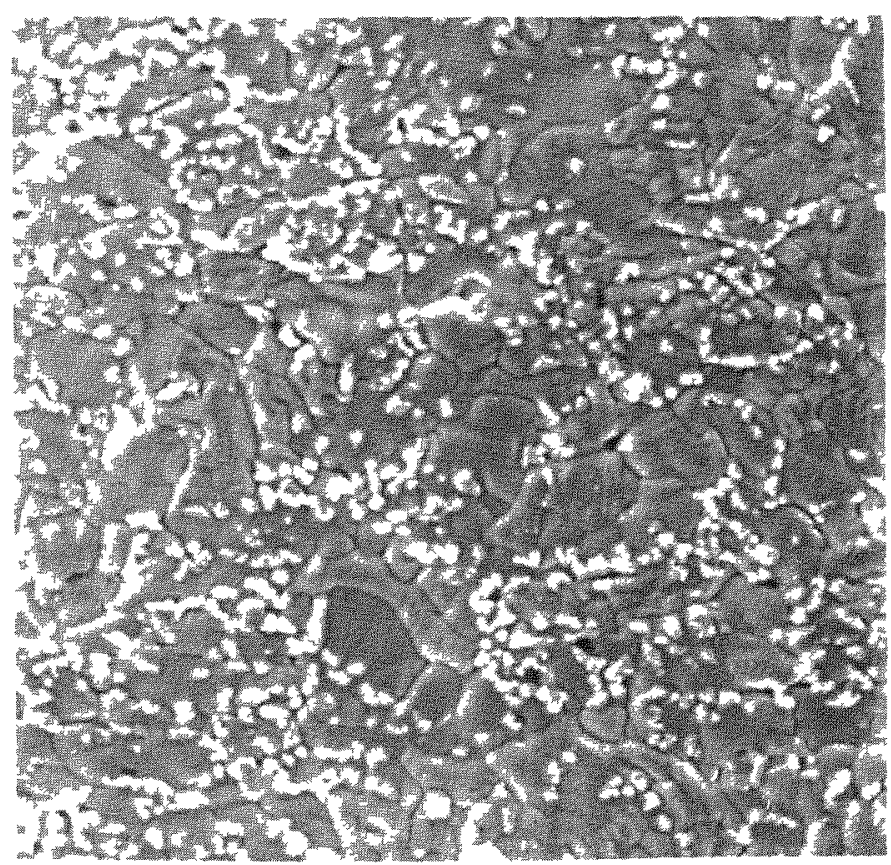

(b) Sodium-exposed (500 hours)

Relative X-ray Intensities: Fe-1.0; Relative X-ray Intensities: Fe-1.0; $\mathrm{Cr}-.54 ; \mathrm{Ni}-.7 ; \mathrm{MO}-.08 \mathrm{Cr}-.45 ; \mathrm{Ni}-.05 ; \mathrm{Mo}-.16$

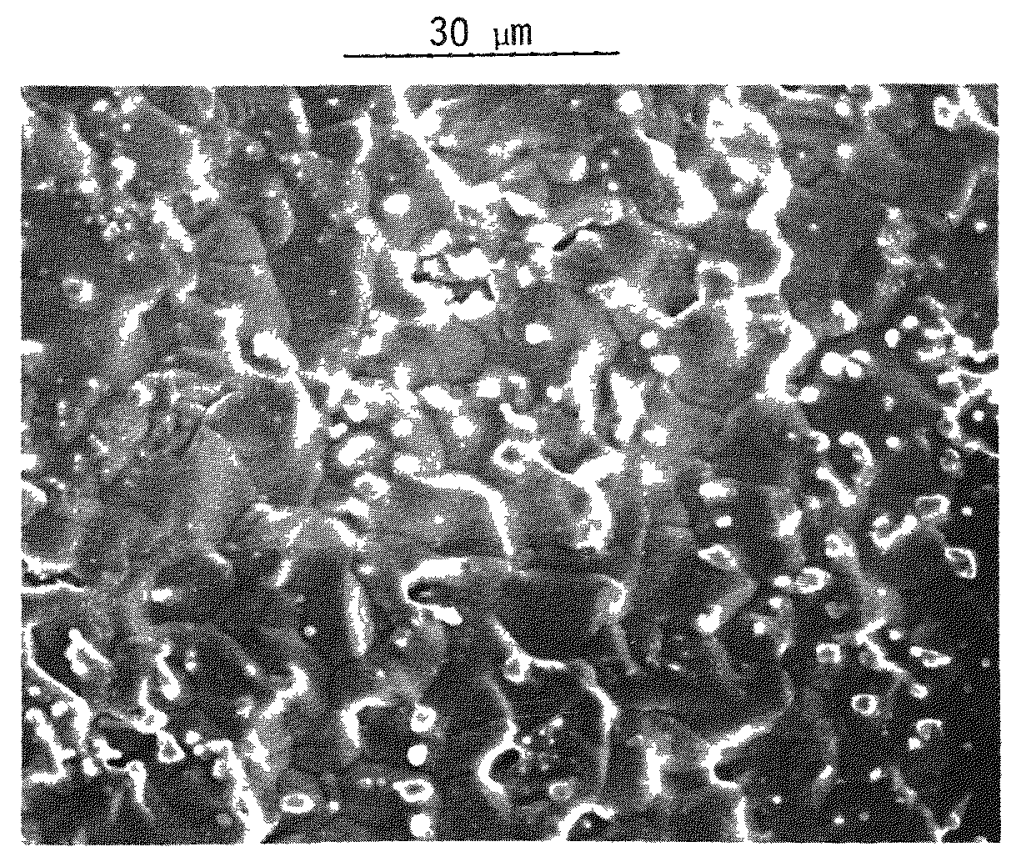

(c) Sodium-exposed (2000 hours)

Relative X-ray Intensities: Fe-1.0; $\mathrm{Cr}-.13 ; \mathrm{Hli-trace}$; Mo-.01

FIĢURE 2. SEM Photographs of As-received and Sodium-exposed AISI 316. 


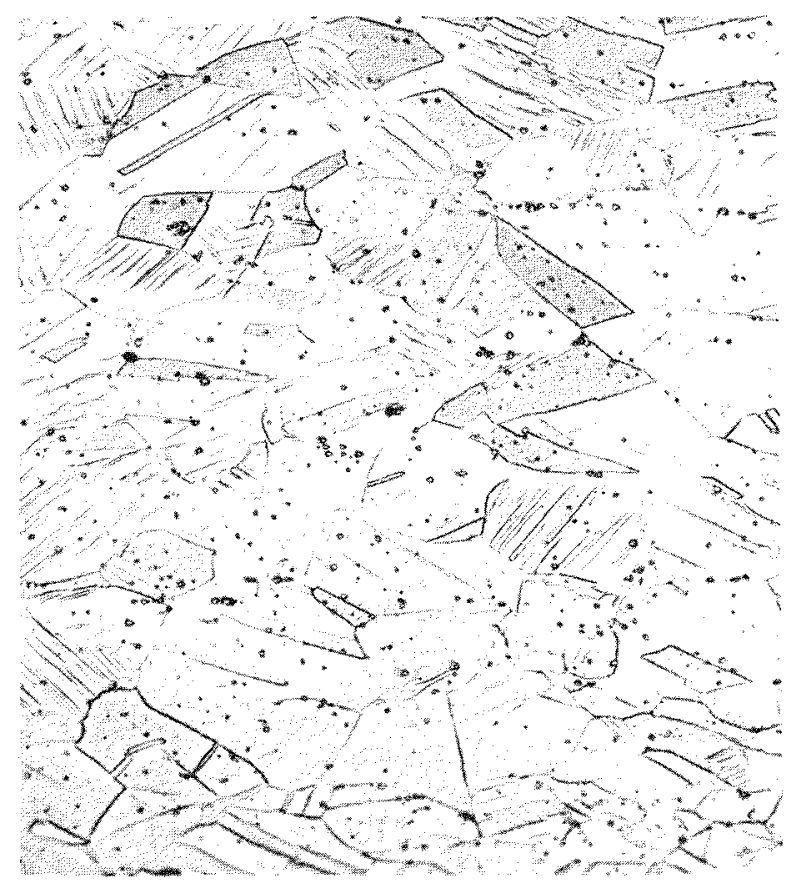

(a) As-received $60 \mu \mathrm{m}$

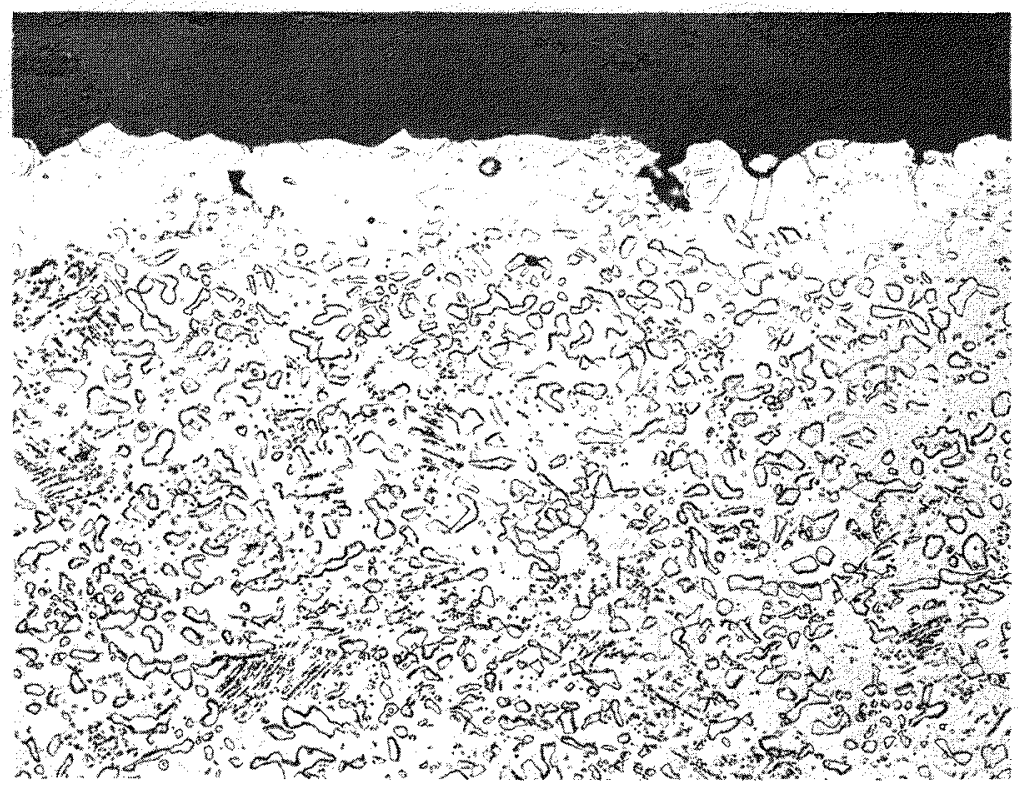

(b) Sodium-exposed (2000 hours)

FIGURE 3. Optical Micrographs of As-received and Sodium-exposed AISI 310. 


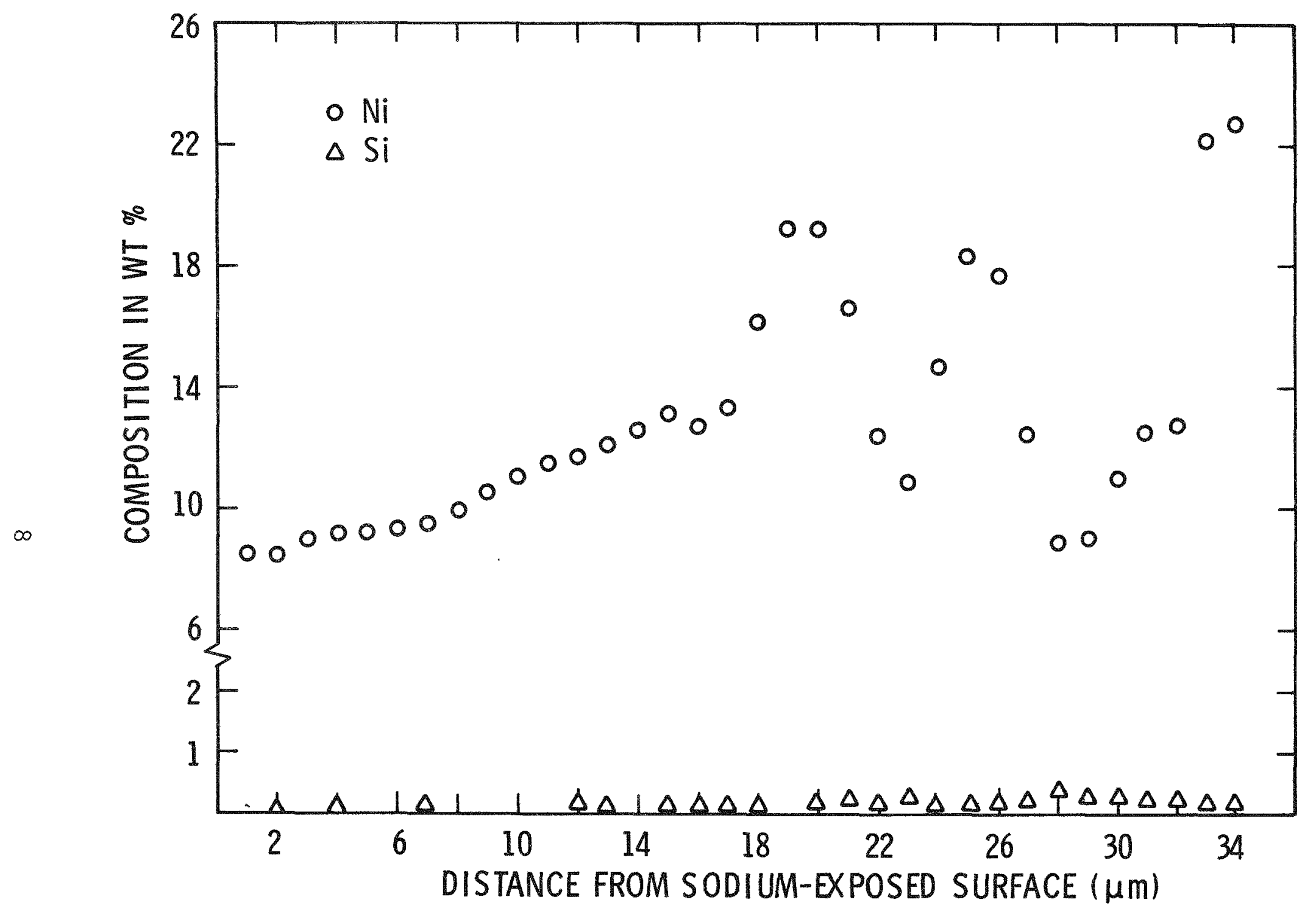

HEDL $7610-49.6$

FIGURE 4. EPMA Profiles of Sodium-exposed (2000 hours) AISI 310. 


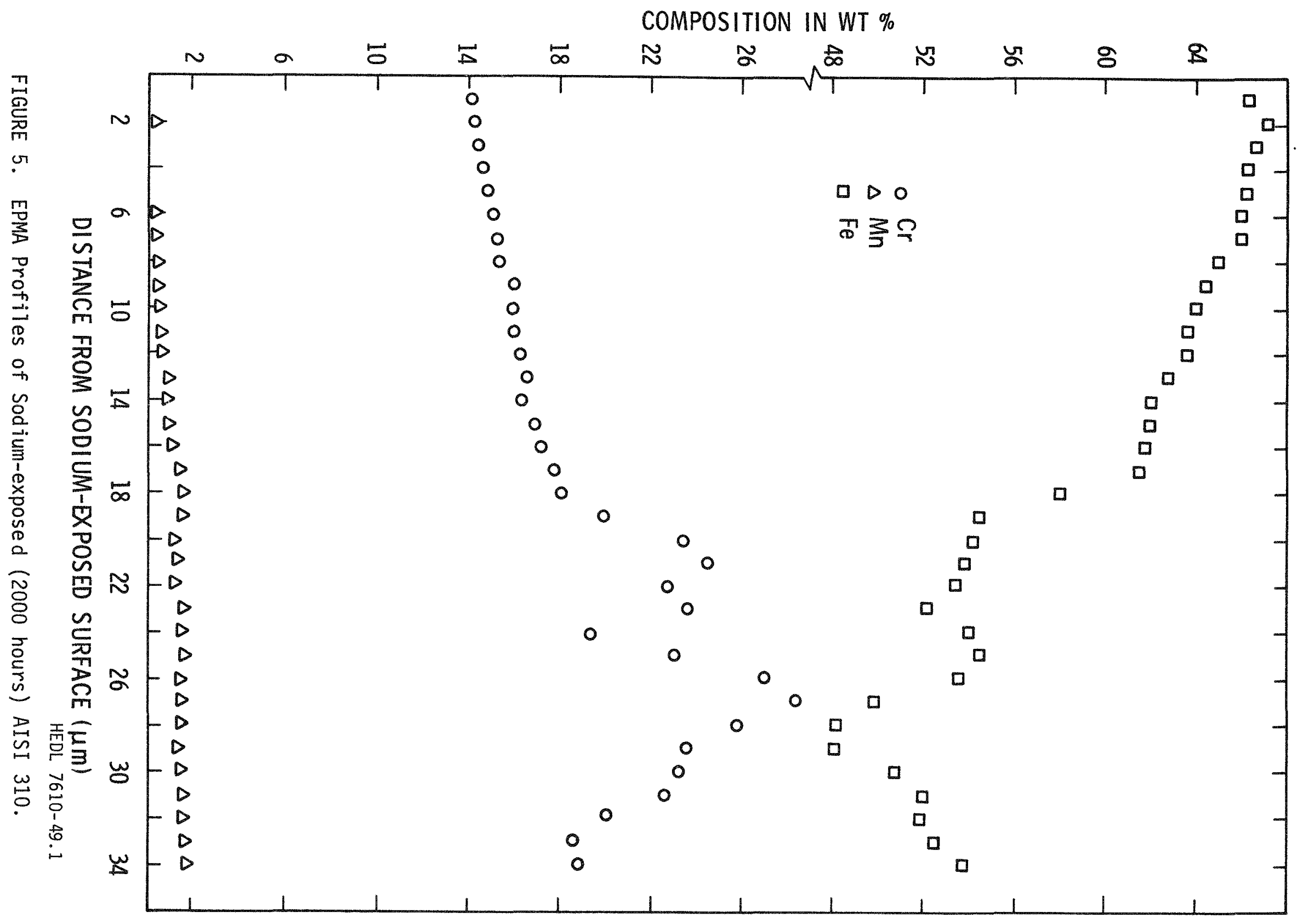


the surface. A careful examination of the figures reveals that the sodiumaffected or depleted zone is approximately 20-25 $\mu \mathrm{m}$. It may also be noted from Figure 3 that the precipitate-free zone extends to about 20-25 $\mu \mathrm{m}$ below the exposed surface. Therefore, sigma formation is seen only in the austenite matrix underneath the depleted zone, as in the case of the reference material. The erratic nature of the EPMA profiles is due to the electron beam traversing the sigma phase precipitates and the matrix alternately.

The SEM data of as-received and sodium-exposed AISI 310 are shown in Figure 6. Grooving of the grain boundaries can be seen here also simi1 ar to AISI 316. A few irregular ly-shaped holes are present at the grain boundaries, suggesting the preferential removal of material by liquid sodium. Relative $\mathrm{X}$-ray intensities revealed the depletion at the corroded surface of $\mathrm{Ni}, \mathrm{Cr}$, and $\mathrm{Si}$, and enrichment of Fe. These data are in excellent agreement with the EPMA data presented above.

The data indicate that exposure of AISI 310 to $700^{\circ} \mathrm{C}$ sodium results in the formation of an iron-rich surface layer and large quantities of undesirable sigma phase precipitates underneath this layer.

\section{AT Toy 330}

The Optical micrographs of Alloy 330 are shown in Figure 7. Although Alloy 330 received the same treatment as AISI 310, there is less evidence of deformation; there is widespread distribution of carbides. This indicates again, as for AISI 310, that the solution treatment was not long enough to permit dissolution of carbides and partial recrystallization has taken place. Exposure to $700^{\circ} \mathrm{C}$ sodium for 2000 hours resulted in the precipitation of carbides outlining the original grain boundaries. Underneath these carbides recrystallized grain structure due to thermal aging in sodium may be noted. Formation of holes along the grain boundaries was observed beneath the exposed surface. The intergranular penetration of sodium extends to a maximum depth of $40 \mu \mathrm{m}$. 


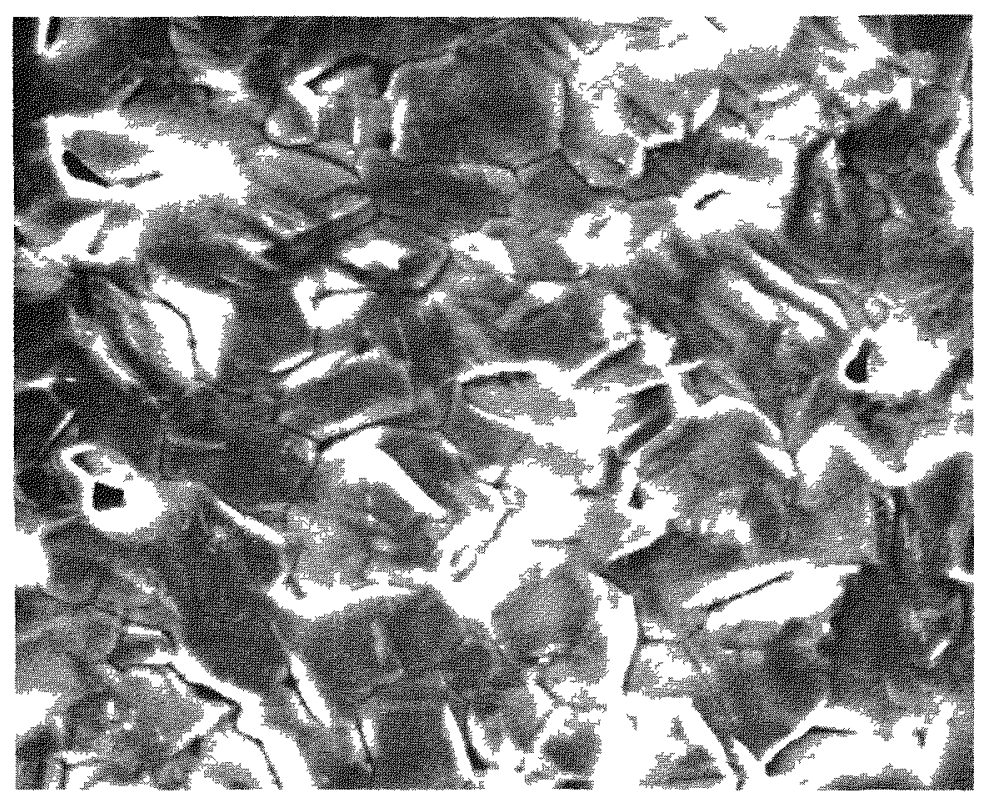

(a) As-received

Relative X-ray Intensities: Fe-1.000; $\mathrm{Cr}-.915 ; \mathrm{Ni}-.285 ; \mathrm{Si}-.015$ $30 \mu$

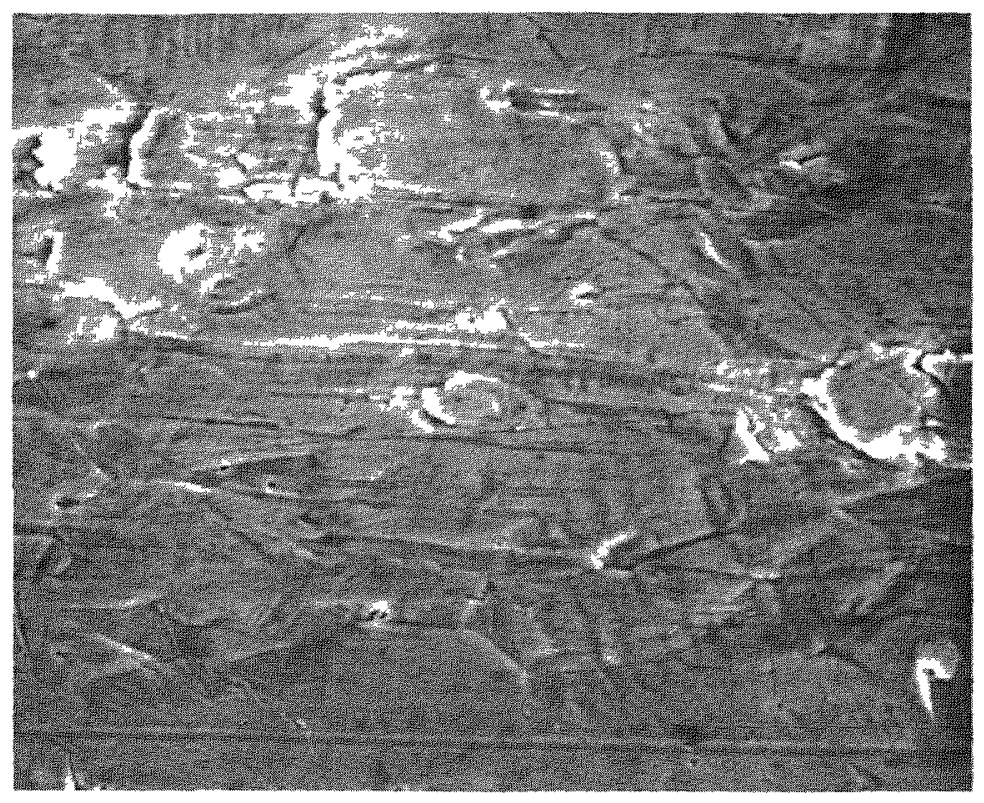

(b) Sodium-exposed

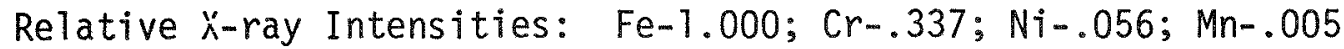

FIGURE 6. SEM Photographs of As-received and Sodium-exposed (2000 hours) AISI 310. 


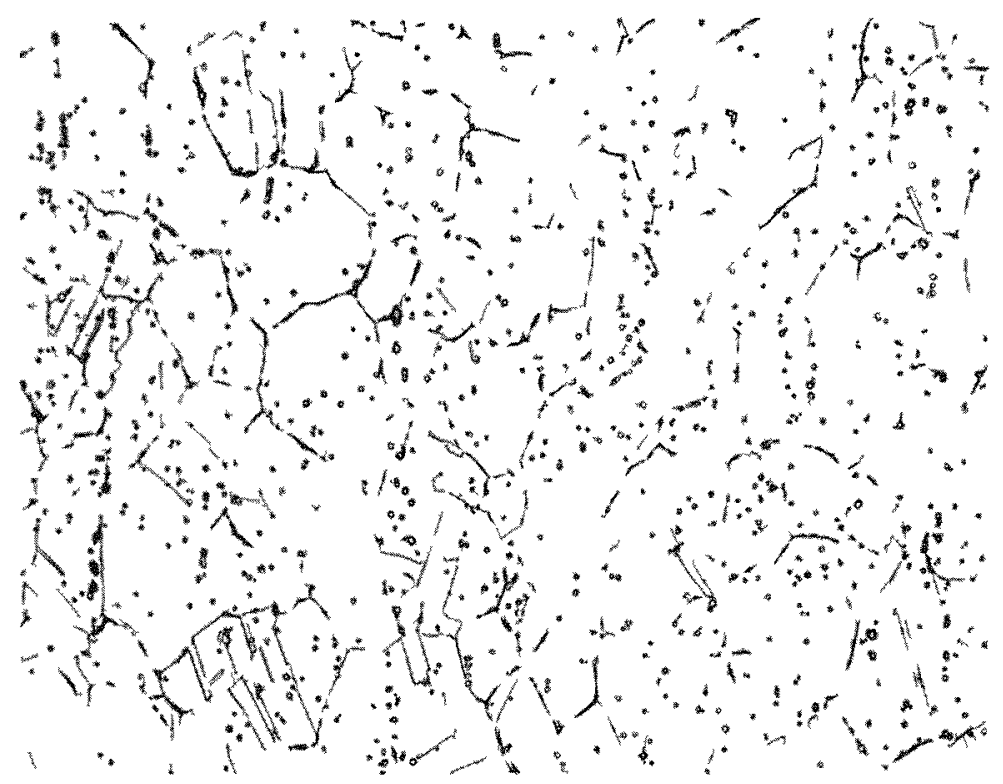

(a) As-received

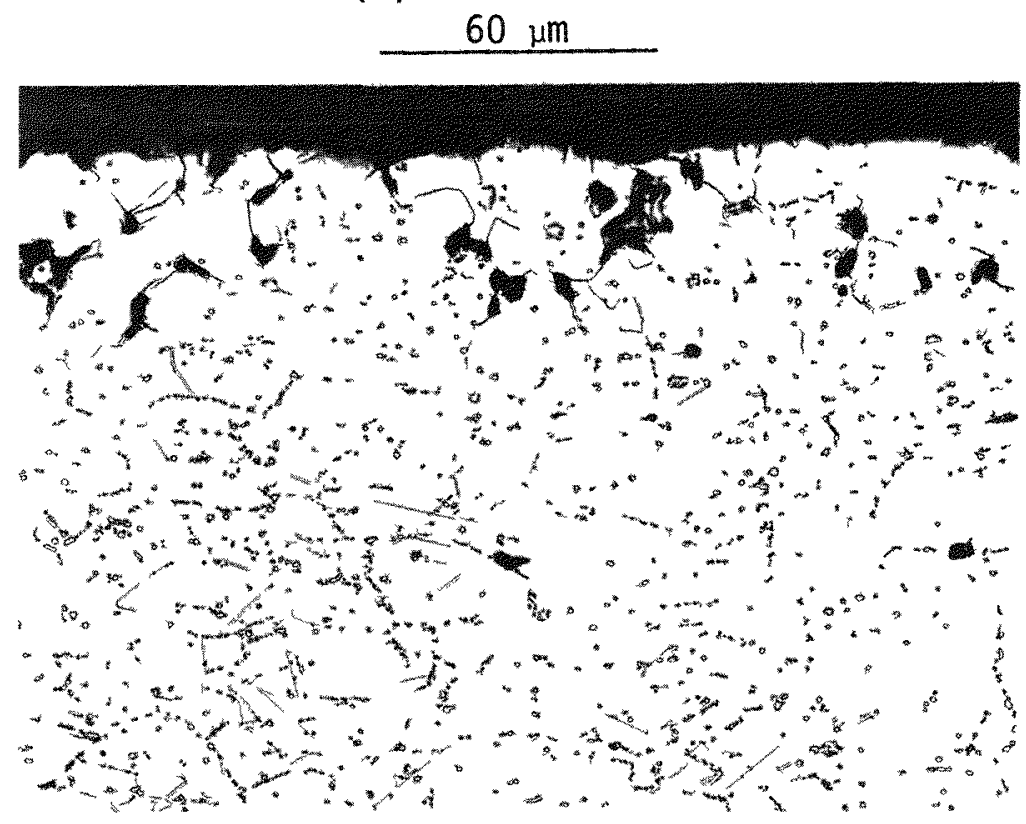

(b) Sodium-exposed (2000 hours)

FIGURE 7. Optical Micrographs of As-received and Sodium-exposed Alloy 330. 
EPMA data of this material (Figures 8-9) indicate that the depleted zone is on $1 y$ about $6 \mu \mathrm{m}$ as compared with 20-25 $\mu \mathrm{m}$ in AISI 310. Enrichment of iron and depletion of $\mathrm{Ni}, \mathrm{Cr}, \mathrm{Mn}$ and $\mathrm{Si}$ can be seen near the surface, similar to AISI 310. However, the nickel depletion is particularly severe in this alloy, which corroborates the high corrosion rate experienced by the alloy.

It can be seen from Figure 10 that the SEM data indicate hole formations at the grain boundaries of the corroded surface. The number of holes is much larger in this case in comparison with AISI 310. Material removal along the grain boundaries had taken place down to a depth of about $40 \mu \mathrm{m}$ as seen earlier in the optical micrographs, and reflects the extremely high corrosion rate this material has experienced. X-ray analysis revealed enrichment of iron and depletion of $\mathrm{Ni}, \mathrm{Cr}$, and $\mathrm{Si}$, which agrees quite well with the EPMA results.

\section{D. $\underline{A-286}$}

A-286 is a precipitation-hardening austenitic alloy which receives its strength by a disperion of $\gamma^{\prime}\left[\mathrm{Ni}_{3}(\mathrm{Al}, \mathrm{Ti})\right]$ upon solution annealing and subsequent aging. This alloy exhibited the lowest corrosion rate $\left(700^{\circ} \mathrm{C}\right)$ among the commercial alloys at low dT/dL conditions.

Optical metallography (Figure 11) of samples exposed to sodium for 2000 hours revealed the equiaxed grain structure of the solution annealed and aged sample. The highly twinned structure of the as-received material is still visible. The slight darkening of some of the grains is due to the presence of underlying unresolved $\gamma^{\prime}$. The number of carbide precipitates has increased considerably from the as-received condition and there is intergranular and transgranular precipitation. A few large cuboidal carbide (TiC) particles are present. The intergranular penetration is limited to on iy $5 \mu \mathrm{m}$. Overaged eta $\left(\mathrm{Ni}_{3} \mathrm{Ti}\right)$ precipitates are expected to appear in the structure after long-term exposure, since the Ti/Al atom ratio is quite high for A-286. 

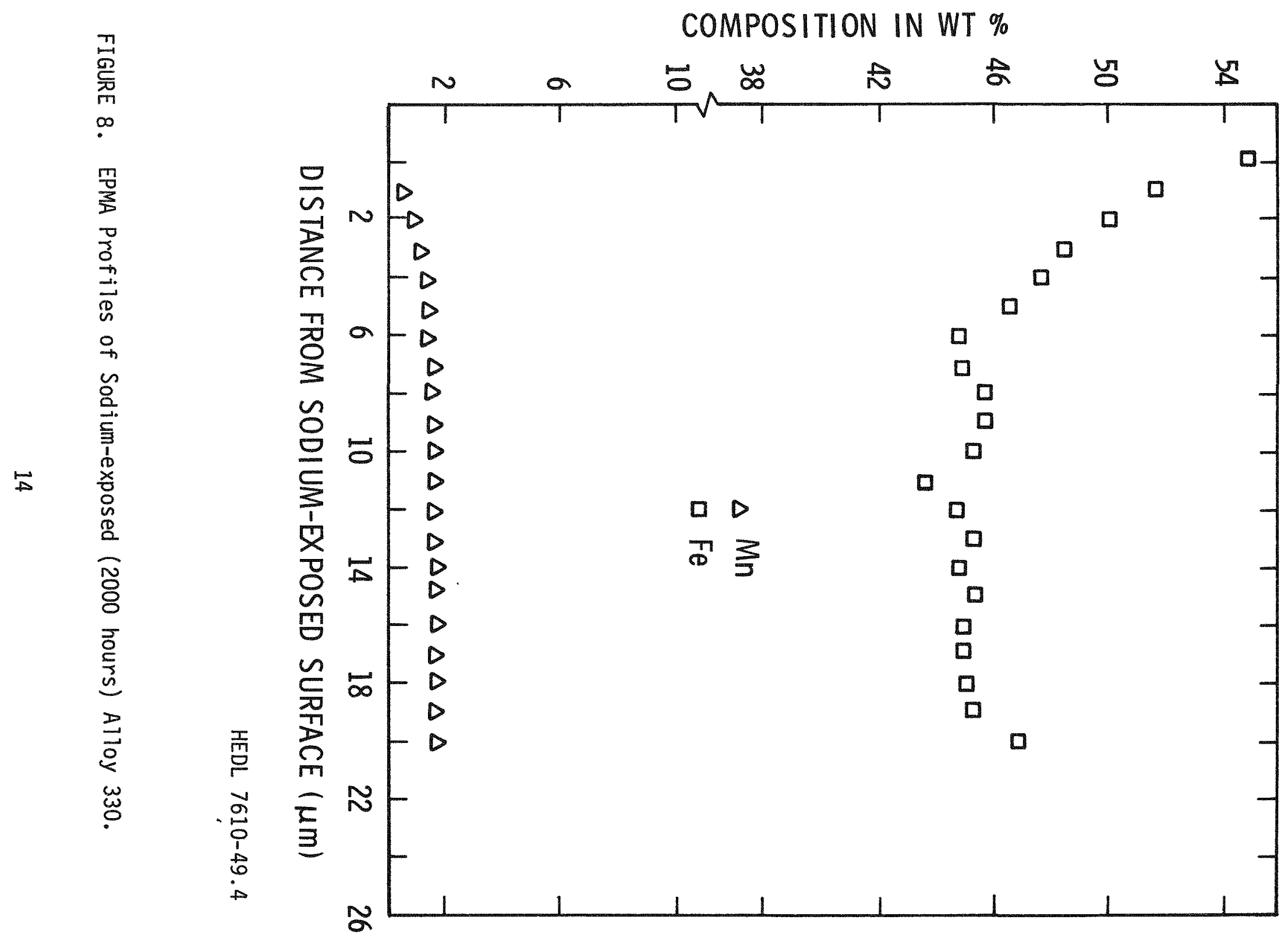


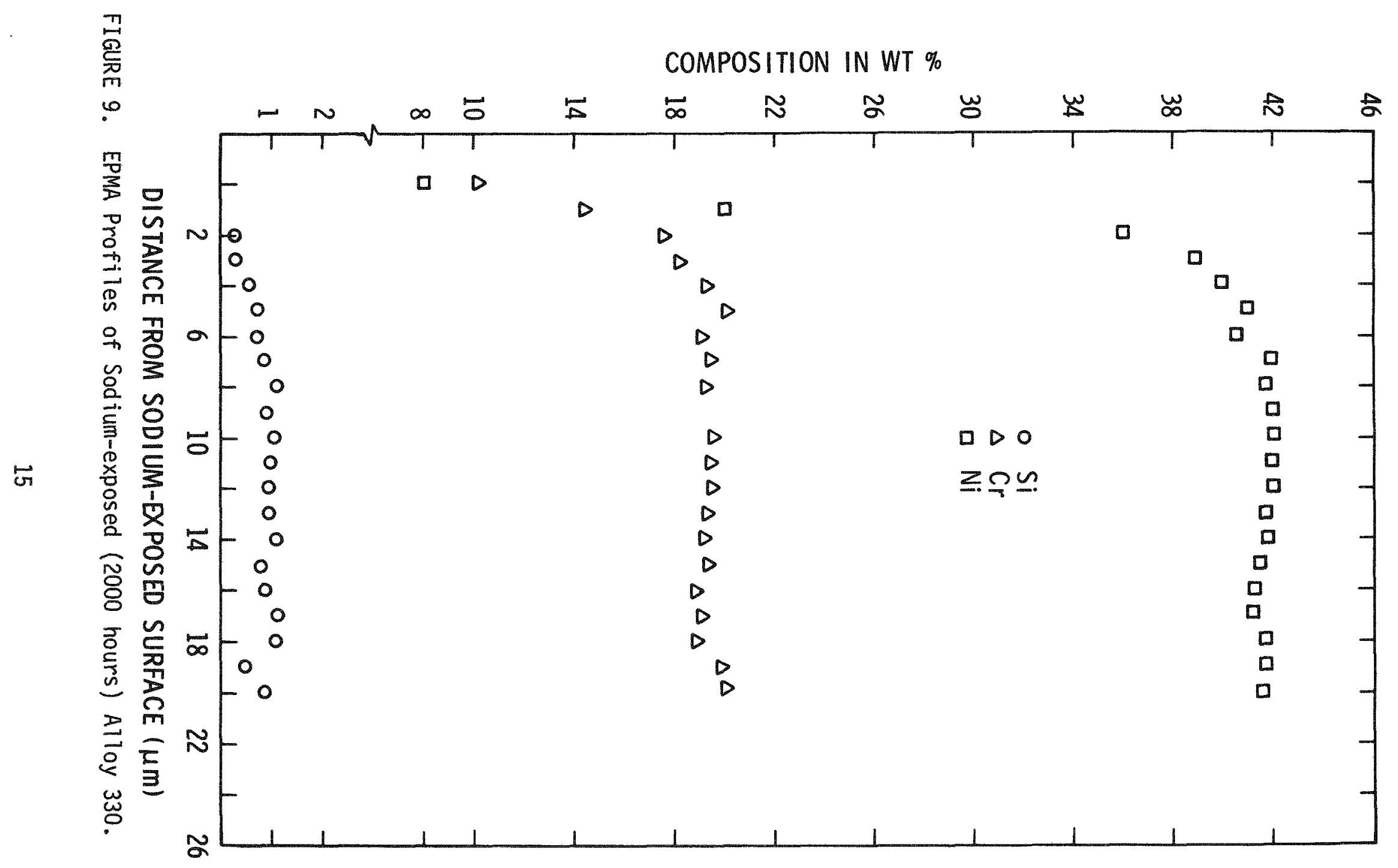




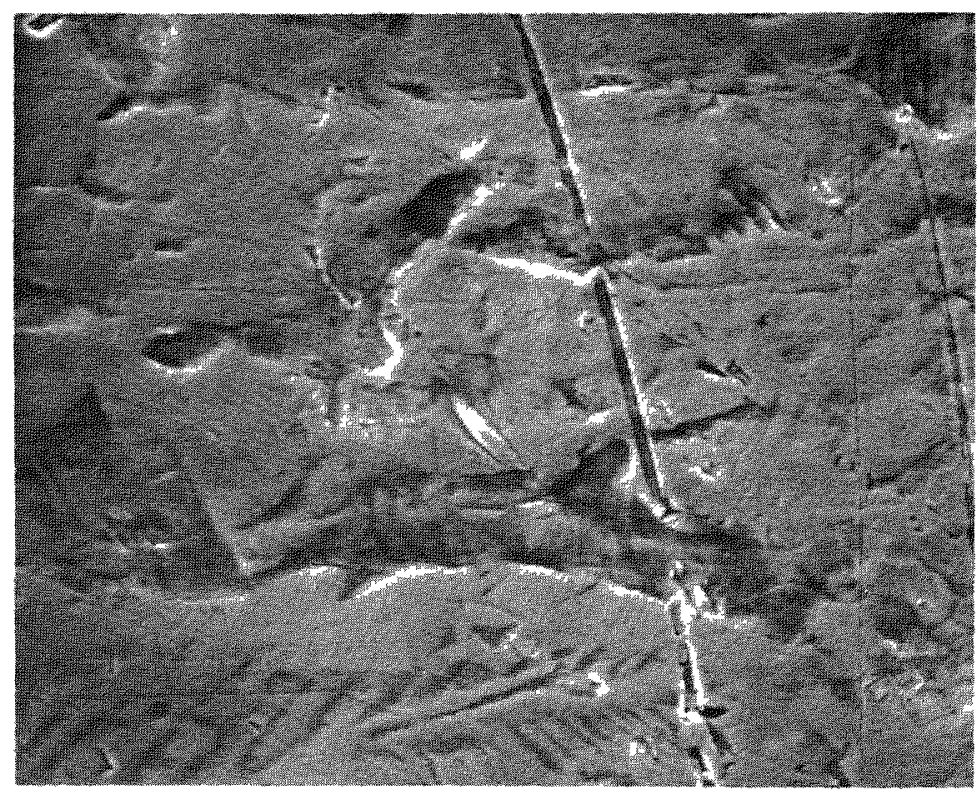

(a) As-received

Relative X-ray Intensities: Fe:1.000; $\mathrm{Cr}-.687 ; \mathrm{Ni}-.519 ; \mathrm{Si}-.019$

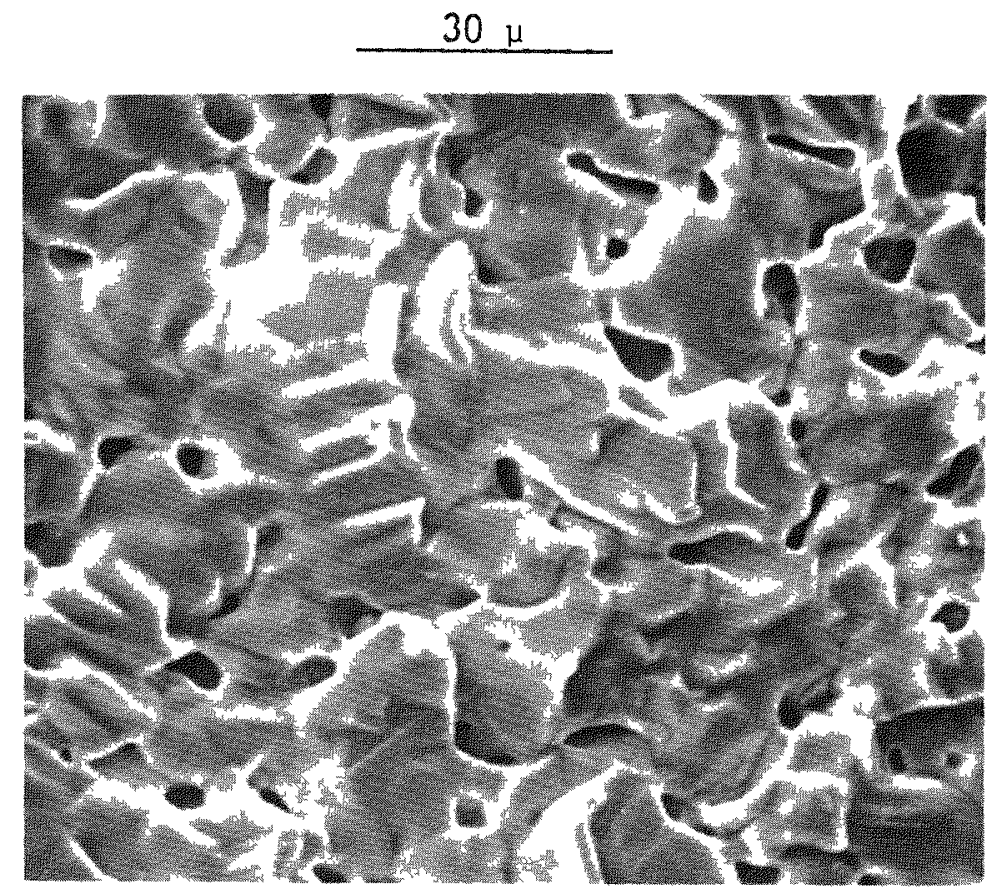

(b) Sodium-exposed

Relative X-ray Ir.tensities: $\mathrm{Fe}-1.000 ; \mathrm{Cr}-.284 ; \mathrm{Ni}-.095$

FIGURE 10. SEM Photographs of As-received and Sodium-exposed (2000 hours) Alloy 330. 


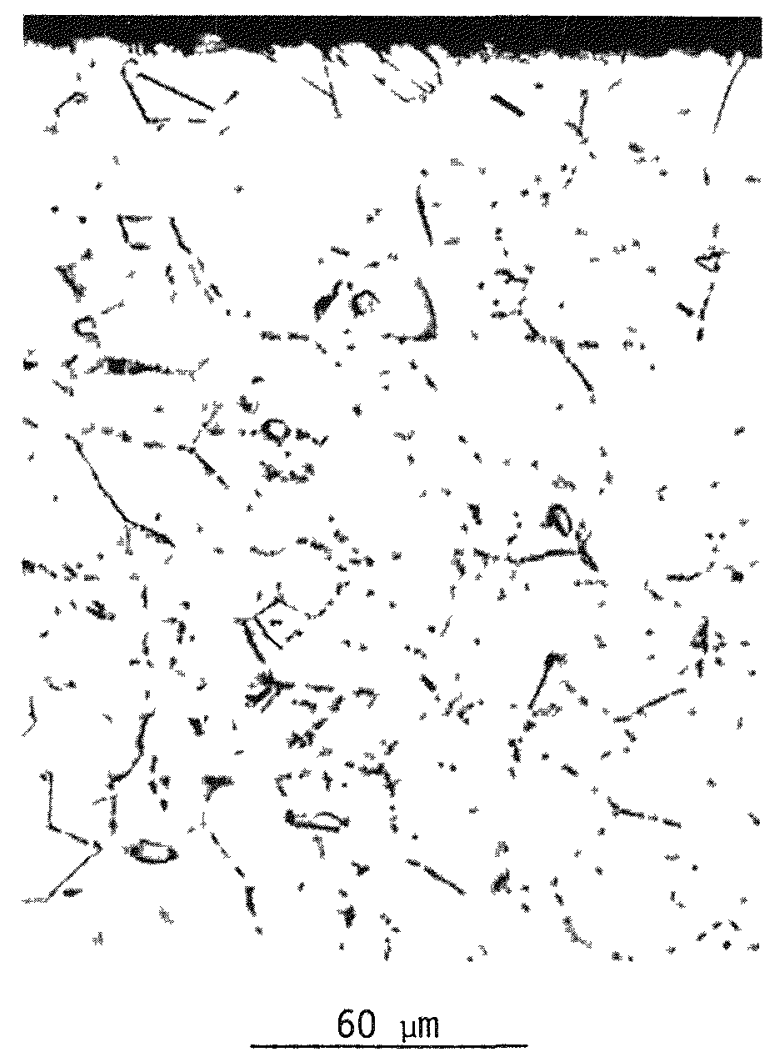

FIGURE 11. Optical Micrograph of Sodium-exposed (2000 hours) A-286. 
Composition profiles of sodium-exposed A-286 obtained from EPMA are shown in Figures 12-13. As before, there is enrichment of iron at the surface along with depletion of $\mathrm{Cr}, \mathrm{Ni}$ and $\mathrm{Ti}$. The concentration of Mo seems to be maintained at a fairly uniform level. The depleted zone is approximately $6 \mu \mathrm{m}$, as with Alloy 330 .

The surface characterization of A-286 performed by SEM is 11 lustrated in Figure 14. Grooving of the grain boundaries is obvious after 500 hours of exposure. A few small holes can be seen after 500 hours, but the number of holes rapidly increases; and after 2000 hours, the entire surface is covered with many larger holes. The small holes became connected with other small holes by material removal from adjacent matrix sites. The X-ray analysis indicates depletion of $\mathrm{Al}, \mathrm{Ti}, \mathrm{Cr}$ and $\mathrm{Ni}$ at the surface. The concentration of Mo seems almost unchanged at the surface, which agrees with the EPMA data. Most of the titanium appears to have been lost during the first 500 hours of exposure.

\section{E. Inconel 706}

Inconel 706 is a $\gamma^{\prime}$ and $\gamma^{\prime \prime}\left(\mathrm{Ni}_{3} \mathrm{Nb}\right)$ precipitation strengthened alloy. However, the as-received material was solution annealed and water quenched and exhibited an ASTM grain size of 3. As shown in Figure 15, a few of the annealing twins are still present after 2000 hours of exposure. Carbide precipitation can be seen at the grain boundaries as well as in the interior of the grains. A few large blocky precipitates of carbide may also be noted. As in the case of A-286, darkening of grains is due to the unresolved $\boldsymbol{\gamma}^{\prime}$ and $\gamma^{\prime \prime}$ underneath. Considerable coarsening of strengthening precipitates has already taken place. Long-term exposure of the material is expected to produce eta $\left(\mathrm{Ni}_{3} \mathrm{Ti}\right)$ needles since the $\mathrm{Ti} / \mathrm{Al}$ atom ratio is quite favorable (approximately 6).

SEM photographs of Inconel 706 are 11 lustrated in Figure $16 . X$-ray analysis data indicate the loss of $\mathrm{Al}, \mathrm{Nb}, \mathrm{Ti}, \mathrm{Cr}$, and $\mathrm{Ni}$. As for $\mathrm{A}-286$, much of the $\mathrm{Ti}$ is lost during the first 500 hours of exposure. The same is true of $\mathrm{Nb}$ 


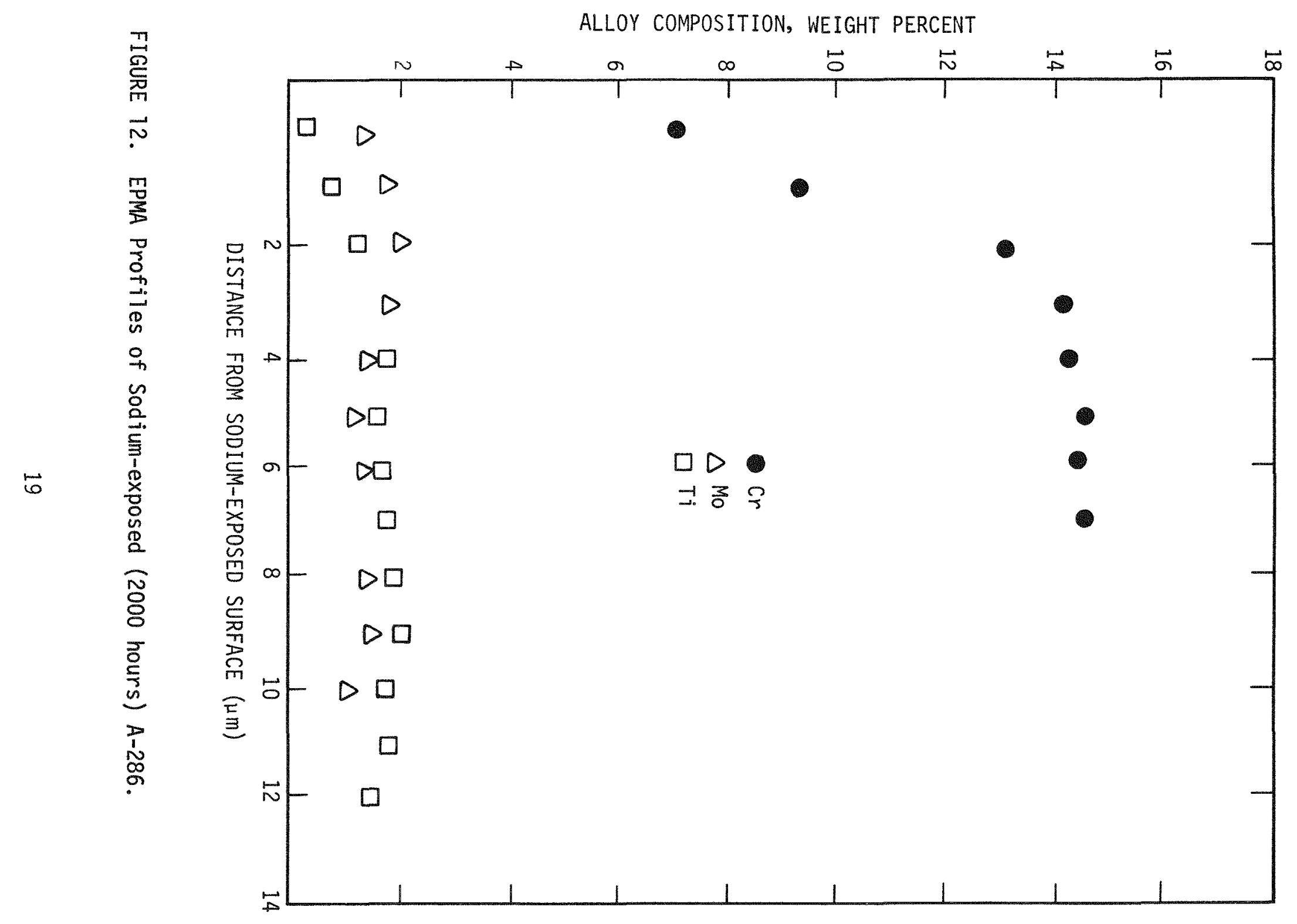




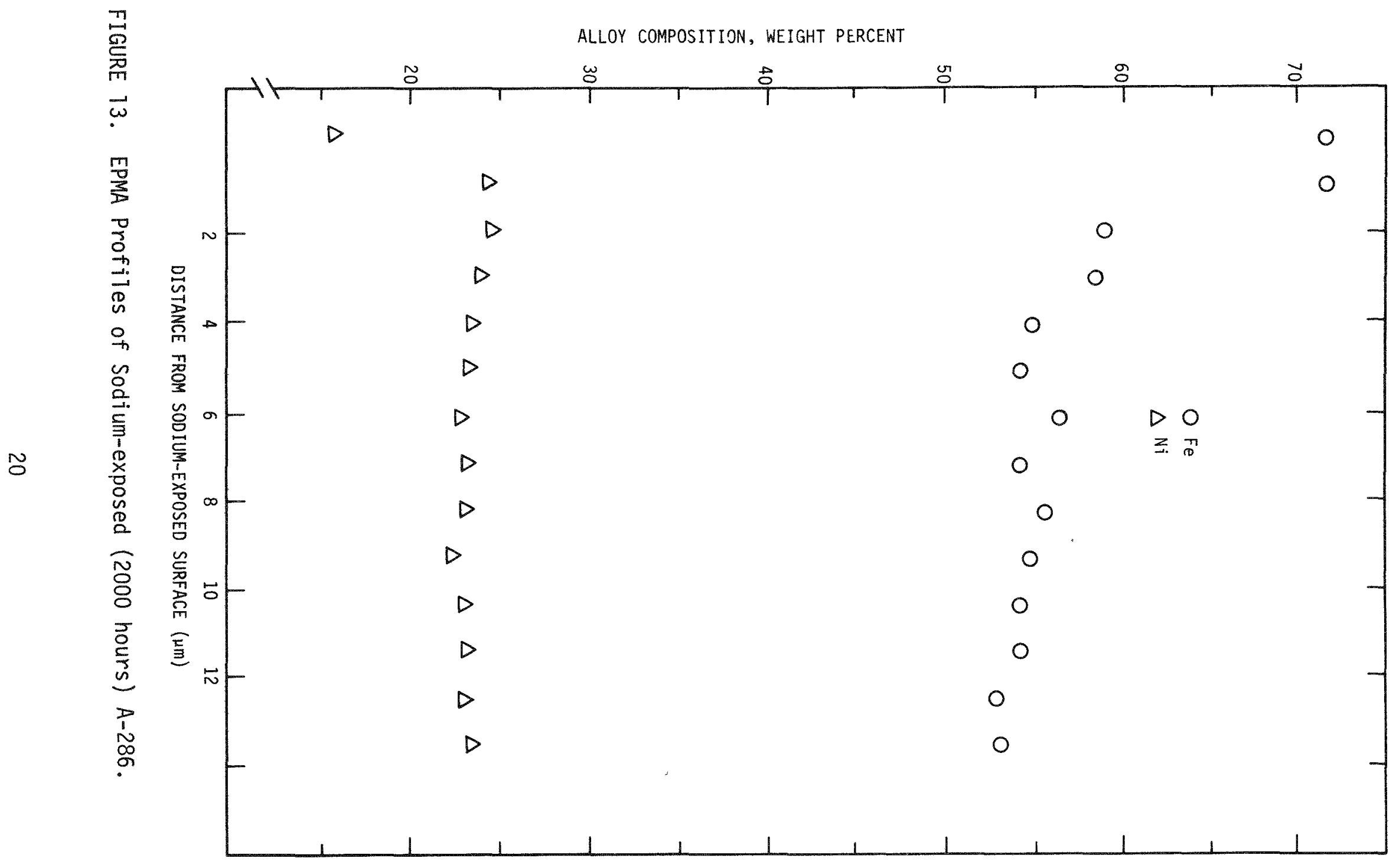




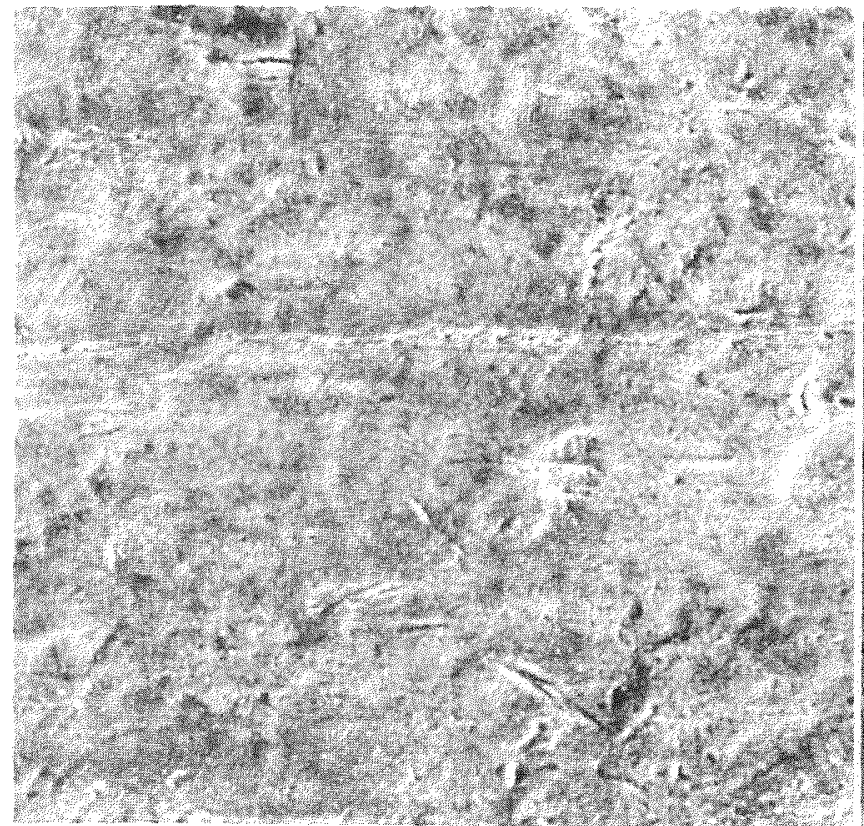

(a) As-received

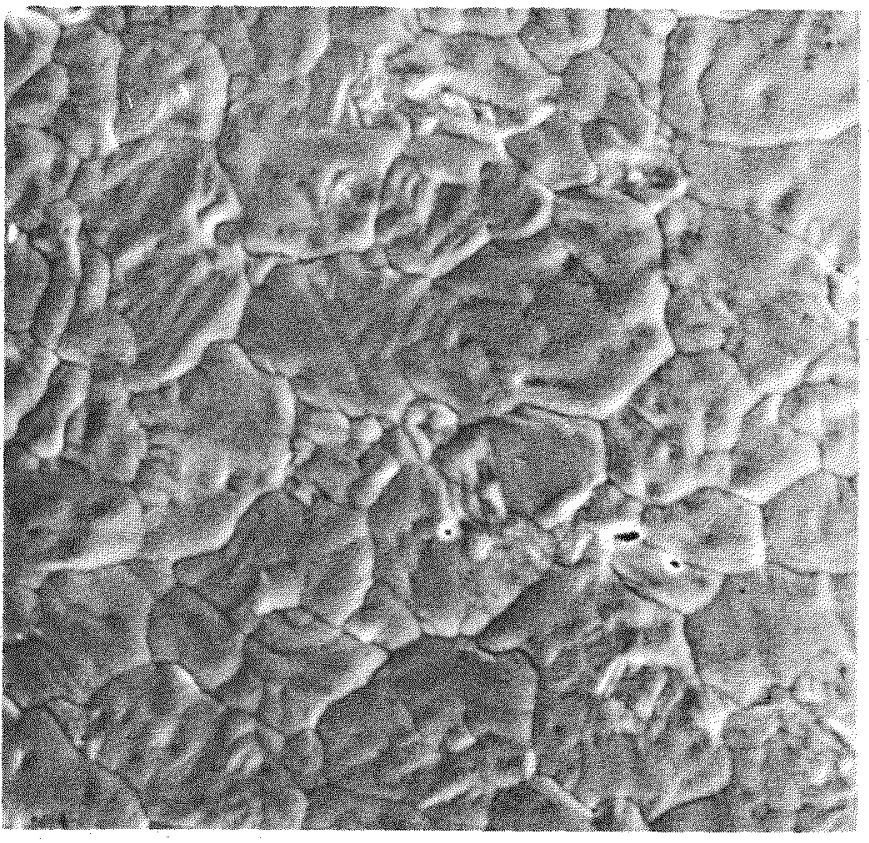

(b) Sodium-exposed (500 hours)

Relative X-ray Intensities: Fe-1.0; Relative X-ray Intensities: Fe-1.0; A1-.05 Cr-.39; Ni-.28; Mo-.02; Ti-.27 Cr-.3i; $\mathrm{Ni}-.017 ; \mathrm{Mo}-.03 ; \mathrm{Ti}-.05 ; \mathrm{Al}-.03$

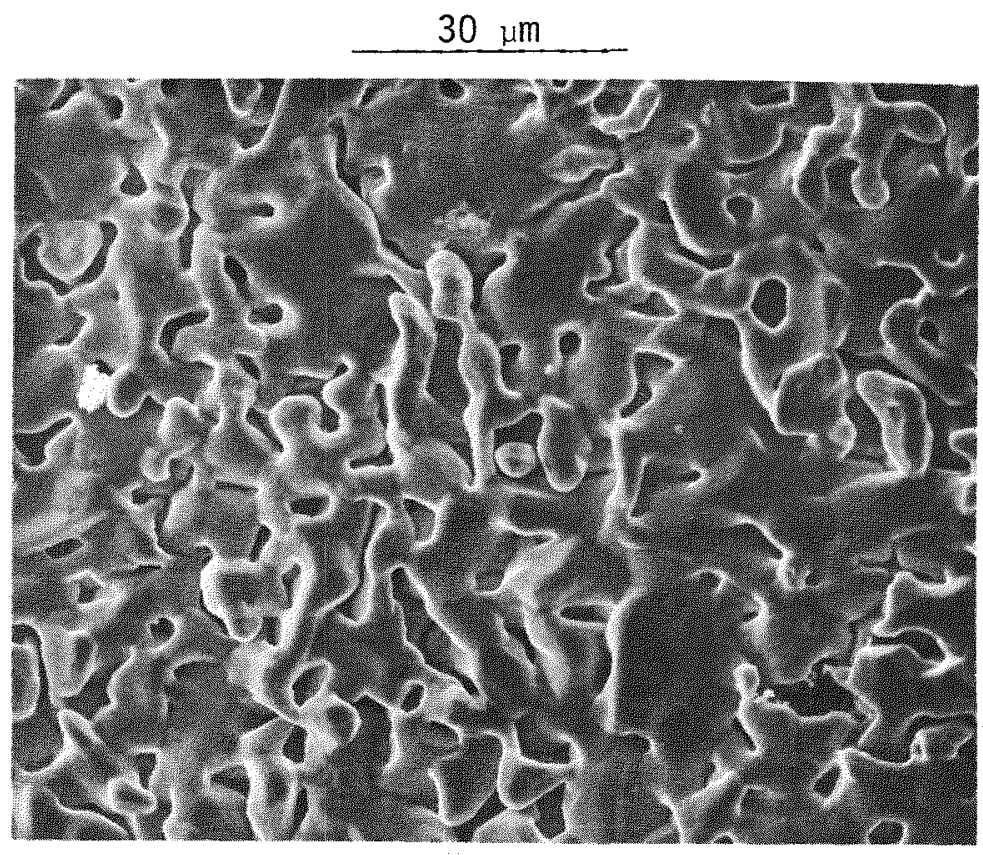

(c) Sodium-exposed (2000 hours)

Relative X-ray Intensities: $\mathrm{Fe}-1.0 ; \mathrm{Cr}-.15 ; \mathrm{Ni}-.01 ; \mathrm{Mo}-.01 ; \mathrm{Ti}-.03 ; \mathrm{Al}-.01$

FIGURE 14. SEM Photographs of As-received and Sodium-exposed A-286. 


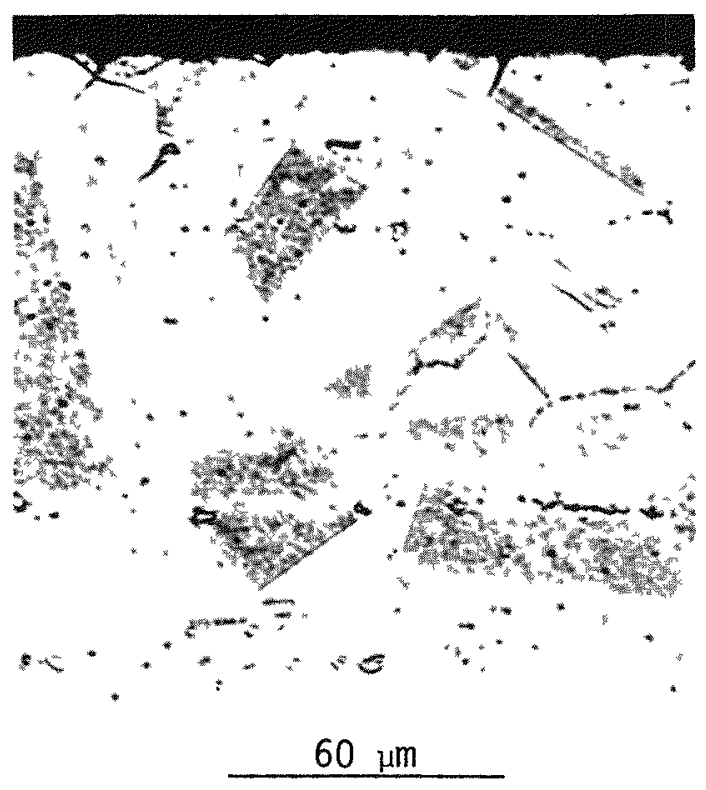

FIGURE 15. Optical Micrograph of Sodium-exposed (2000 hours) Inconel 706. 


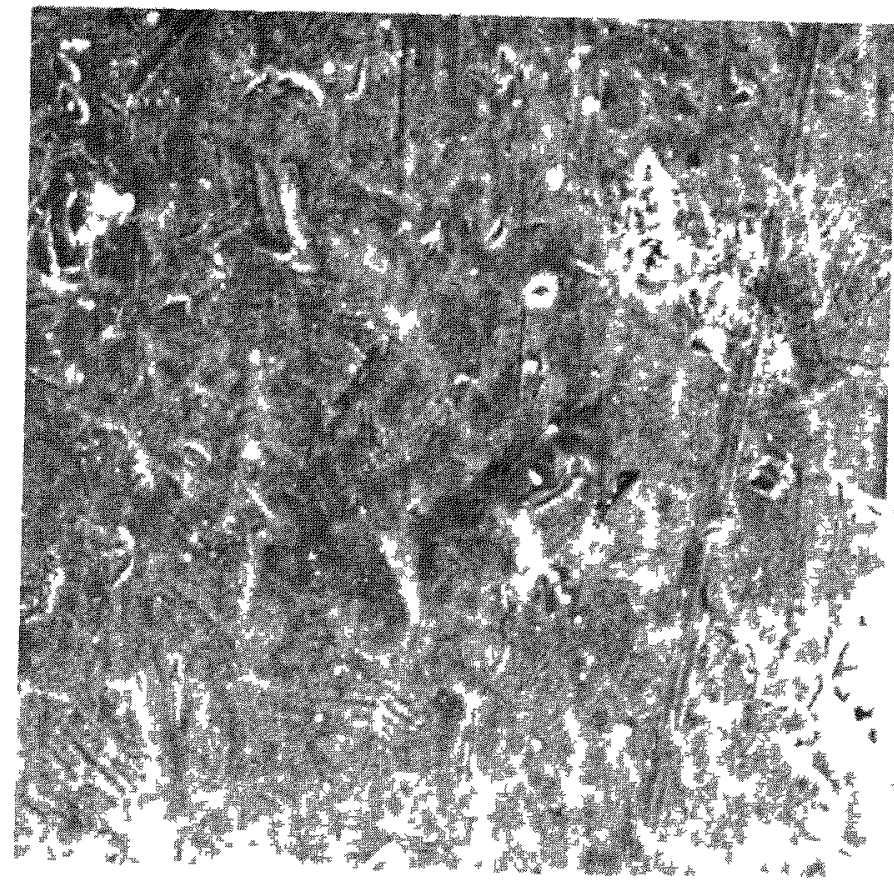

(a) As-received

Relative X-ray Intensities: Fe- 1.0 ; $\mathrm{Cr}-.55 ; \mathrm{Ni}-.58 ; \mathrm{Nb}-.04 ; \mathrm{Ti}-.13 ; \mathrm{AT}-.07$

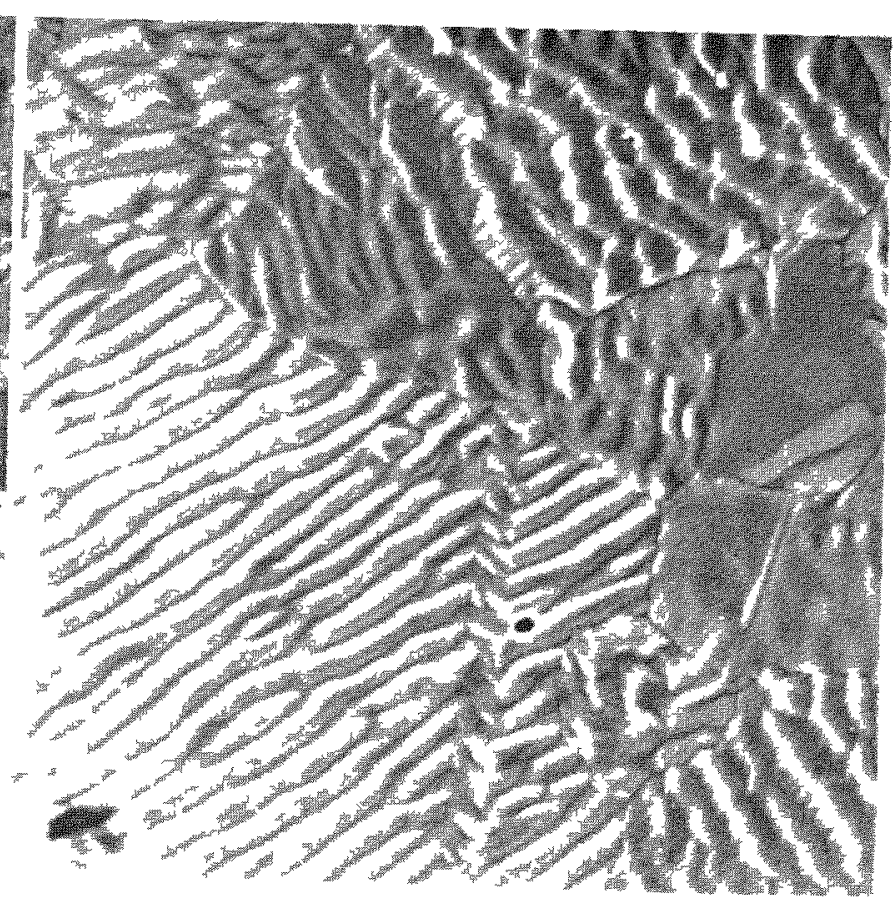

(b) Sodium-exposed (500 hours)
Relative $X$-ray Intensities: $\mathrm{Fe}-1.0$; $\mathrm{Cr}-.29 ; \mathrm{Ni}-.23 ; \mathrm{Nb}-.01 ; \mathrm{Ti}-.05 ; \mathrm{AT}-.04$

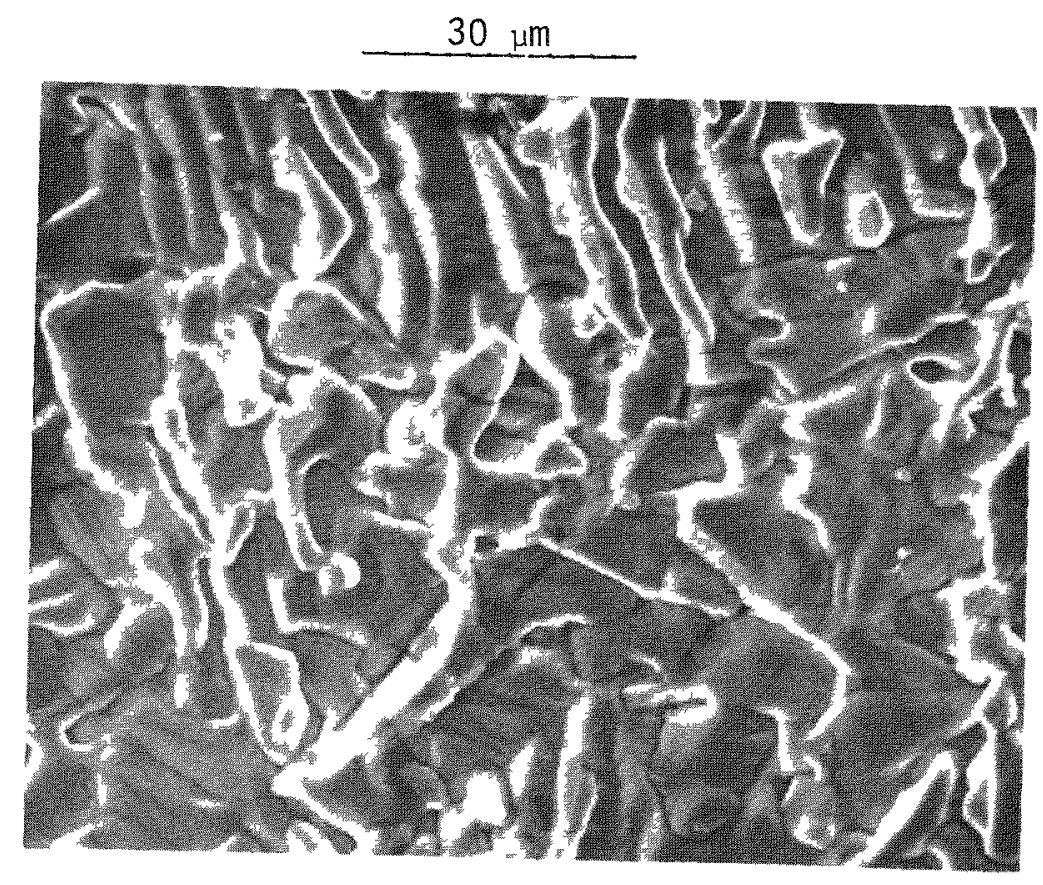

(c) Sodium-exposed (2000 hours)

Relative X-ray Intensities: $\mathrm{Fe}-1.0 ; \mathrm{Cr}-.25 ; \mathrm{Ni}-.11 ; \mathrm{Nb}-.01 ; \mathrm{Ti}-.05 ; \mathrm{Al}-.03$

FIGURE 16. SEM Photographs of As-received and Sodium-exposed Inconel 706. 
also. The appearance of the corroded surface indicates that corrosion of this alloy is grain-orientation dependent. This is clearly seen from the surface exposed for 500 hours. Each grain is composed of parallel striations that are dependent on grain orientation. After 2000 hours, however, the grain-orientation dependence of striations is not as apparent due to increasing material removal. The surface structure after 2000 hours is somewhat similar to that of $A-286$ which has the lowest corrosion rate.

\section{F. Nimonic PE16}

Nimonic PE16, similar to A-286, is also a $\gamma^{\prime}$ former. Solution anneal at $1080^{\circ} \mathrm{C}$ followed by aging at $900^{\circ} \mathrm{C}$ followed by further aging at $750^{\circ} \mathrm{C}$ is the standard heat treatment recommended by the manufacturer. Aging at $900^{\circ} \mathrm{C}$ resulted in carbide $\left(\mathrm{M}_{23} \mathrm{C}_{6}\right)$ precipitation as grain boundary networks. The final aging step at $750^{\circ} \mathrm{C}$ is aimed at producing the strengthening $\gamma^{\prime}$ precipitates. The as-received material displays a highly twinned structure, a result of the solution treatment. Presence of carbide stringers is also seen as a result of the fabrication procedure. The grain size, ASTM-4, is a consequence of the long holding time (4 hours) at $1080^{\circ} \mathrm{C}$.

Exposure to $700^{\circ} \mathrm{C}$ sodium for 2000 hours led to coarsening of $\gamma^{\prime}$ as in the case of Inconel 706 (Figure 17). The twinned structure of the as-received material is still apparent and a few large cuboidal TiC precipitates may also be noted. The alloy showed intergranular attack to a maximum depth of $25 \mu \mathrm{m}$. Precipitates of overaged eta are not expected to form even after long exposure times since the Ti/Al atom ratio is quite low $(0.5)$.

The composition vs. depth profiles of Nimonic PE16 are given in Figures 18 and 19. As before, the surface shows depletion of alloying elements $\mathrm{Ni}$ and $\mathrm{Cr}$, and enrichment of $\mathrm{Fe}$. In addition, Mo enrichment similar to the reference material was also observed. The concentration of the element titanium seems generally uniform. The depleted zone is approximately $5 \mu \mathrm{m}$ after 2000 hours of exposure. 


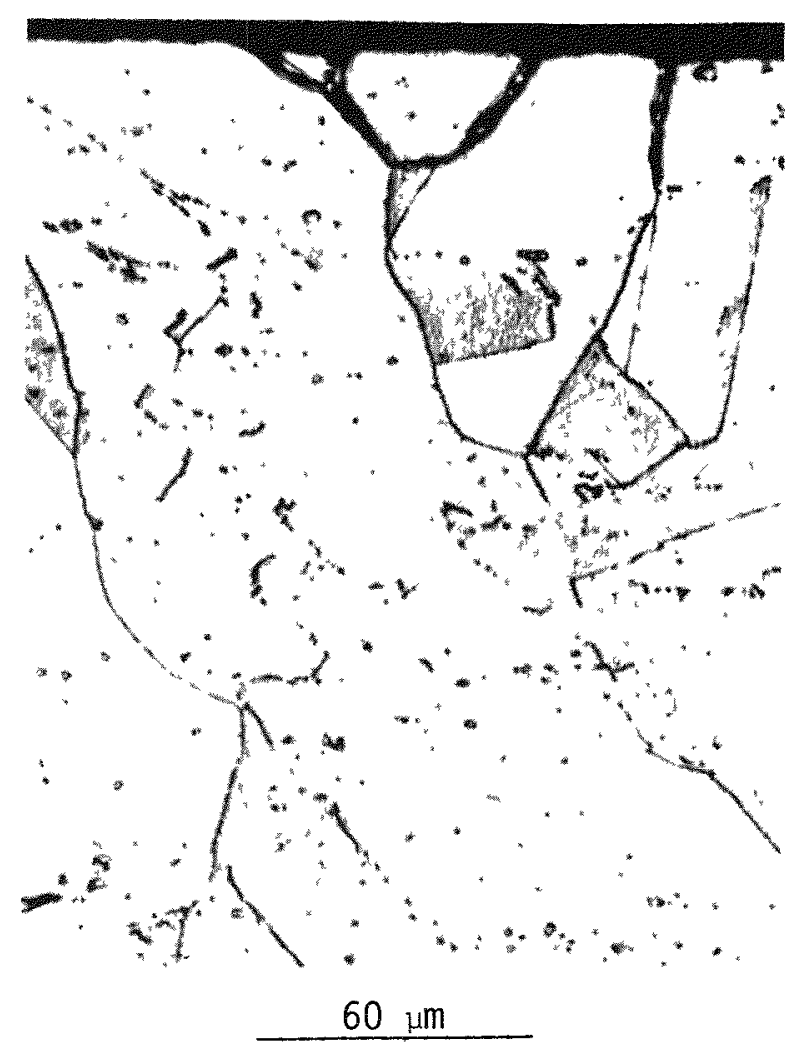

FIGURE 17. Optical Micrograph of Sodium-exposed (2000 hours) Nimonic PET6. 


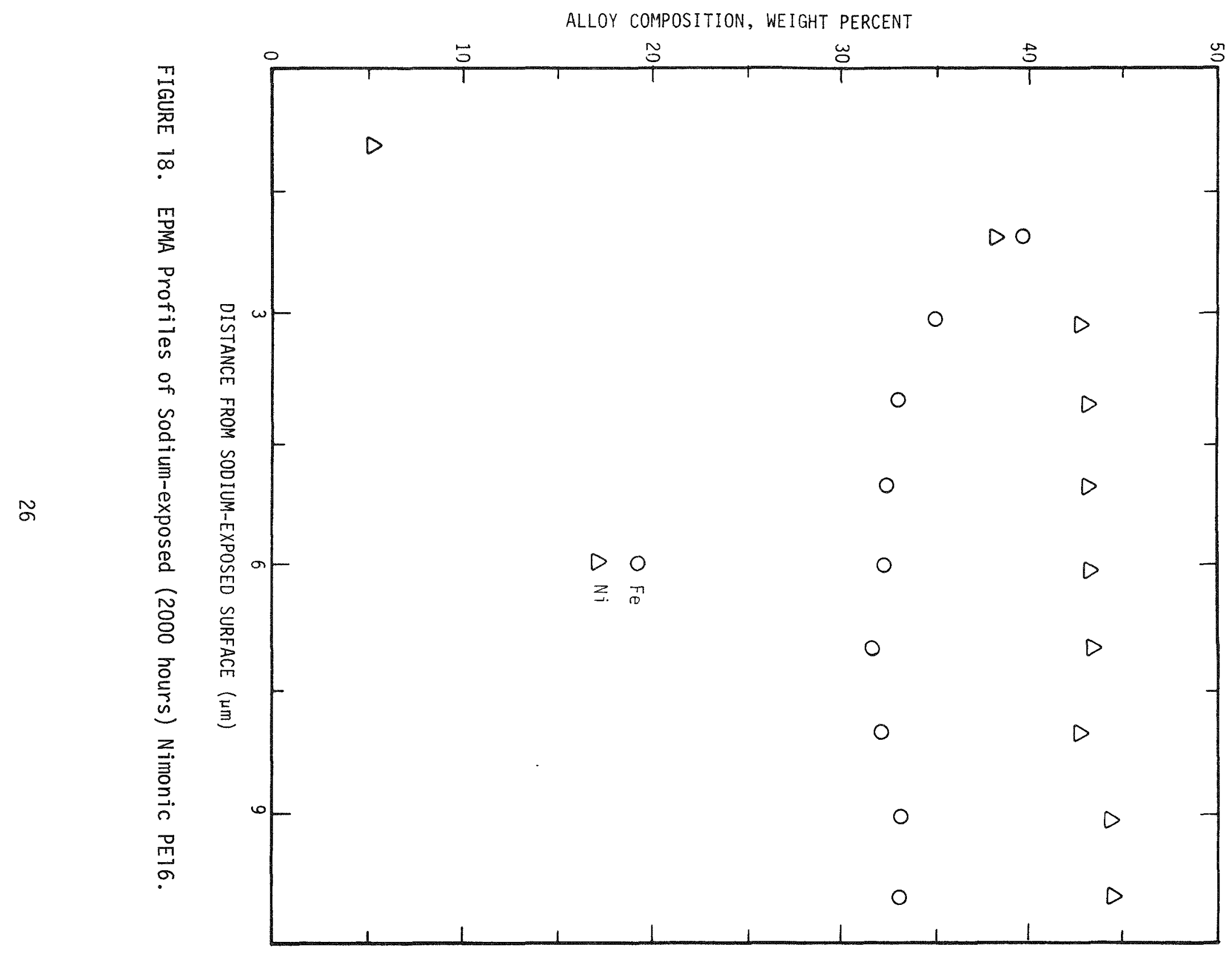




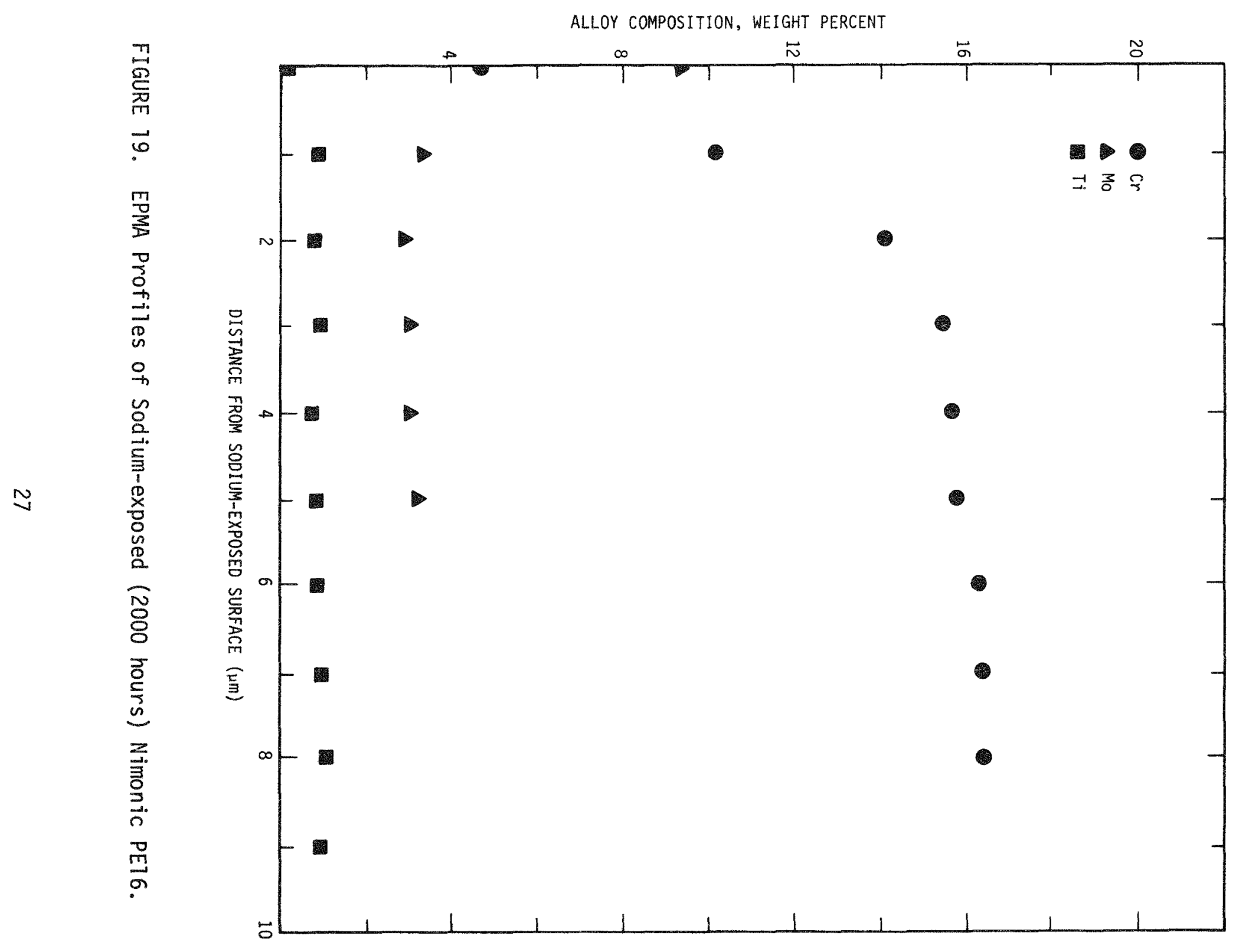


The SEM data of Nimonic PEI6 is displayed in Figure 20. The relative X-ray intensities of as-received and sodium-exposed surfaces indicate depletion of $\mathrm{Ni}, \mathrm{Cr}, \mathrm{Ti}$ and $\mathrm{Al}$, and enrichment of $\mathrm{Fe}$ and Mo. Most of the $\mathrm{Al}$ and $\mathrm{Ti}$ seem to have been lost during the first 500 hours of exposure. A comparison of these data with the EPMA data given in Figures 18 and 19 reveals that the surface of the as-received material was enriched with titanium and possibly also aluminum. Subsequent exposure to sodium leached away these elements quickly during the early hours of exposure and then a fairly uniform level of these elements is maintained. This seems to be especially true with titanium. Increasing evidences of surface enrichments of $\mathrm{Ti}$ and also $\mathrm{Al}$ in the as-received sheet materials have been obtained in this program on other advanced cladding alloys.

As shown in Figure 20, the surface is characterized by the appearance of micron-size nodes. Similar to the reference material, these nodes are enriched in Fe and Mo. Unlike AISI 316, the area scan of this material shows a further increase in Mo concentration at the surface after 2000 hours as compared with that after 500 hours. This suggests that the nodes are more resistant to sodium in Nimonic PE16 and cannot be washed away as easily as in AISI 316. It is also worth noting that the concentration of Mo in Nimonic PE16 is 3.3 wt\% as compared with 2.5 wt\% in AISI 316.

\section{G. $M-813$}

Alloy M-813 was obtained in sintered form. The alloy received the same heat treatment as Nimonic PE16. The compositions of the two alloys are quite similar. Due to an increase in $\mathrm{Cr}$ and Mo contents, a decrease in $\mathrm{Ni}$, and a fairly low $C$ content of M-813 compared with Nimonic PE16, sigma phase formation can be expected in M-813.

As seen in Figure 21, the as-received material displays duplex grain size. The first aging step at $900^{\circ} \mathrm{C}$ promoted a high density of carbide precipitates across the grains and as grain boundary networks. Exposure to $700^{\circ} \mathrm{C}$ sodium for 2000 hours led to the formation of sigma phase island networks around the austenite grains. 


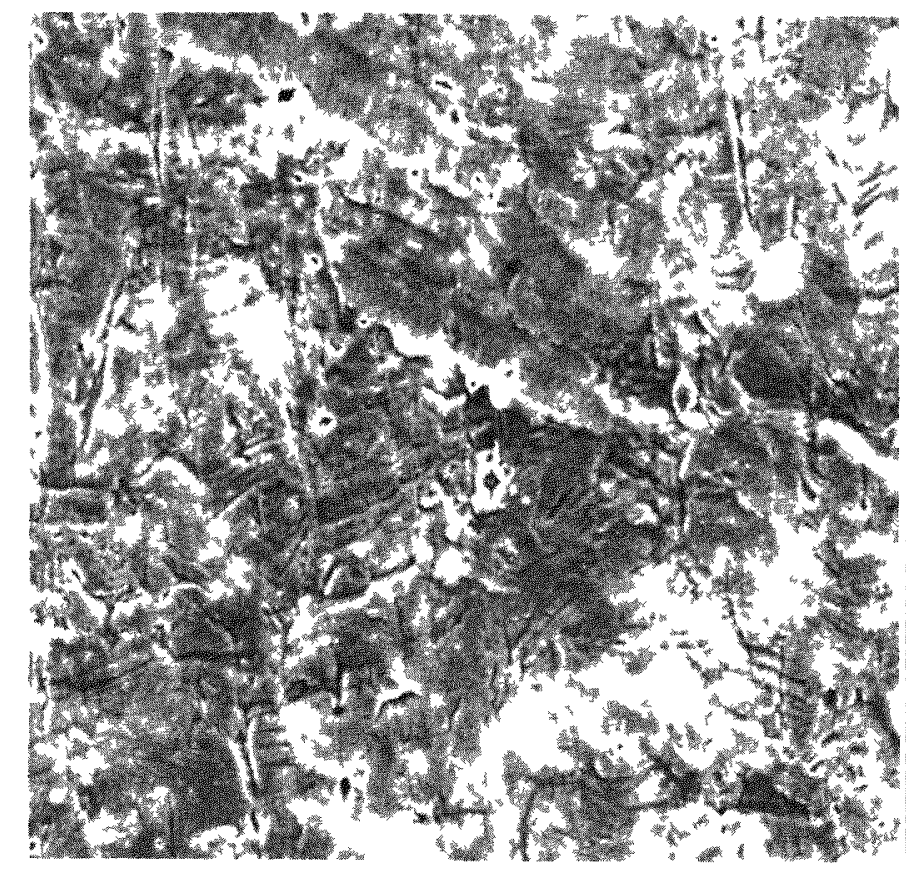

(a) As-received

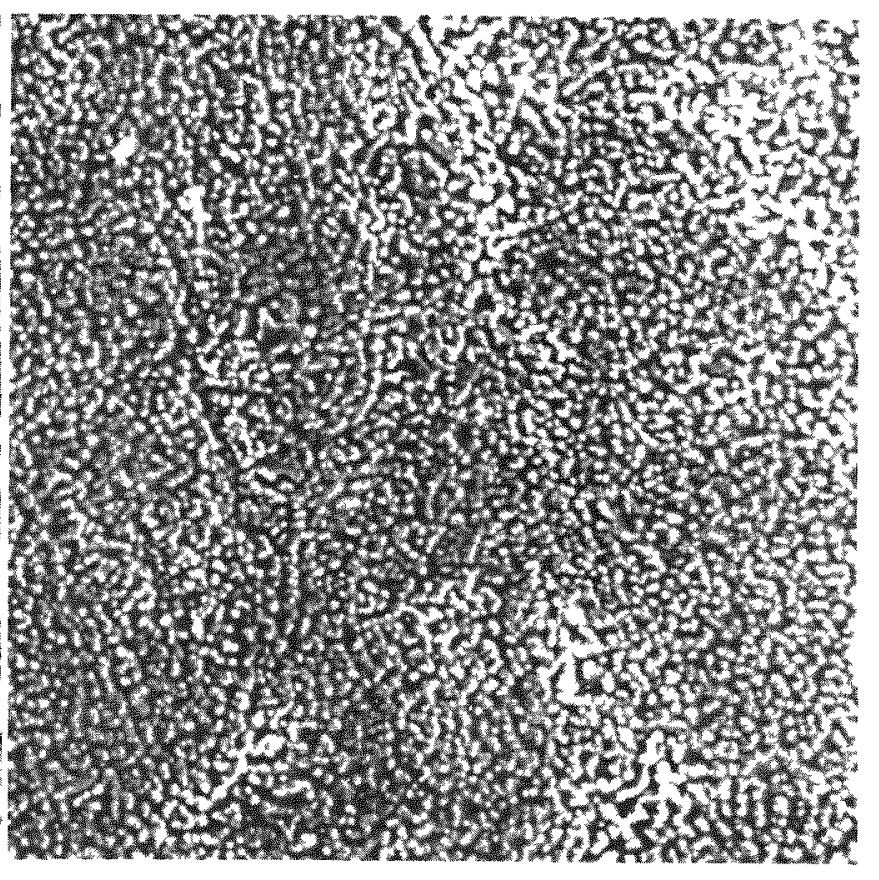

(b) Sodium-exposed (500 hours)

Relative X-ray Intensities: $\mathrm{Fe}-1.0$; $\mathrm{Cr}-.74 ; \mathrm{Ni}-.8, \mathrm{MO}-.1 ; \mathrm{Ti}-.62 ; \mathrm{Al}-.12$

Relative X-ray Intensities: Fe-1.0; $\mathrm{Cr}-.57 ; \mathrm{Ni}-.57 ; \mathrm{Mo}-.19 ; \mathrm{Ti}-.07 ; \mathrm{A} 1-.08$

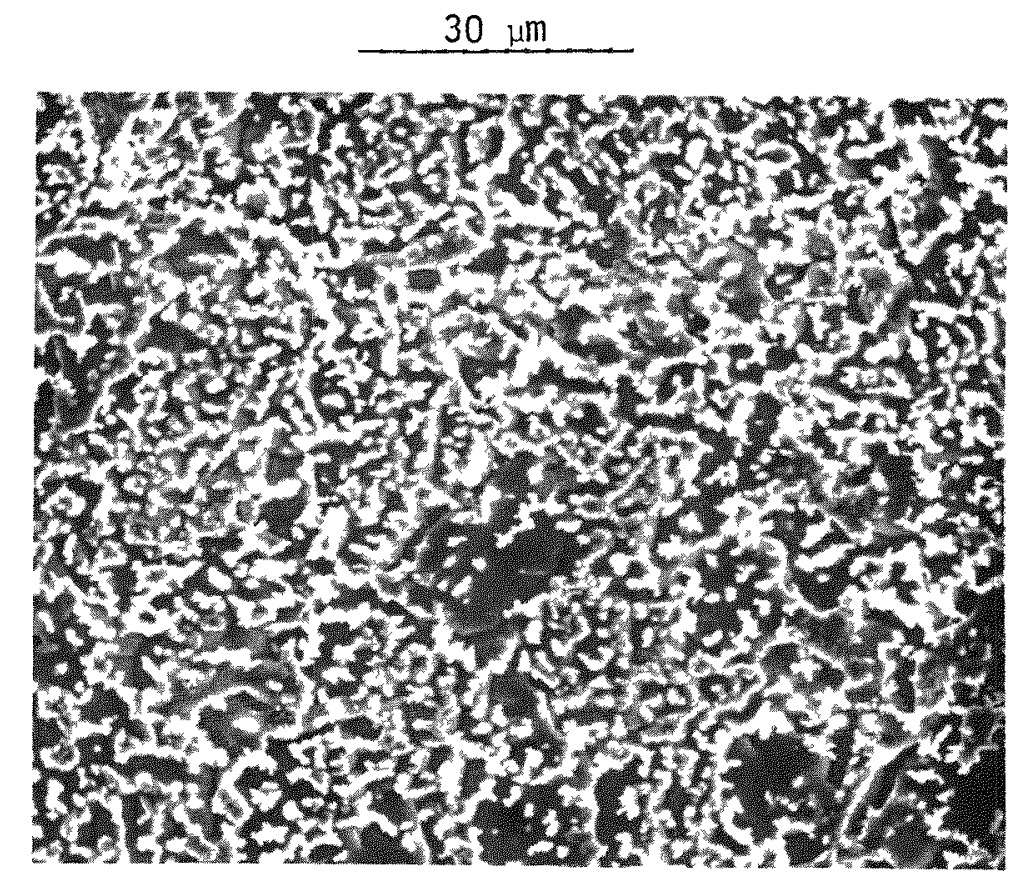

(c) Sodium-exposed (2000 hours)

Relative

X-ray Intensities: Area Scan--Fe-1.0; $\mathrm{Cr}-.27 ; \mathrm{Ni}-.07 ; \mathrm{Mo}-.48 ; \mathrm{Ti}-.09 ; \mathrm{AT}-.07$ Node--Fe-1.0; $\mathrm{Cr}-.16 ; \mathrm{Ni}-.02 ; \mathrm{Mo}-.13 ; \mathrm{A} 1-.03$

Matrix--Fe-1.0; $\mathrm{Cr}-.19 ; \mathrm{Ni}-.1 ; \mathrm{Mo}-.04 ; \mathrm{Al}-.02$

FIGURE 20. SEM Photographs of As-received and Sodium-exposed Nimonic PE16. 


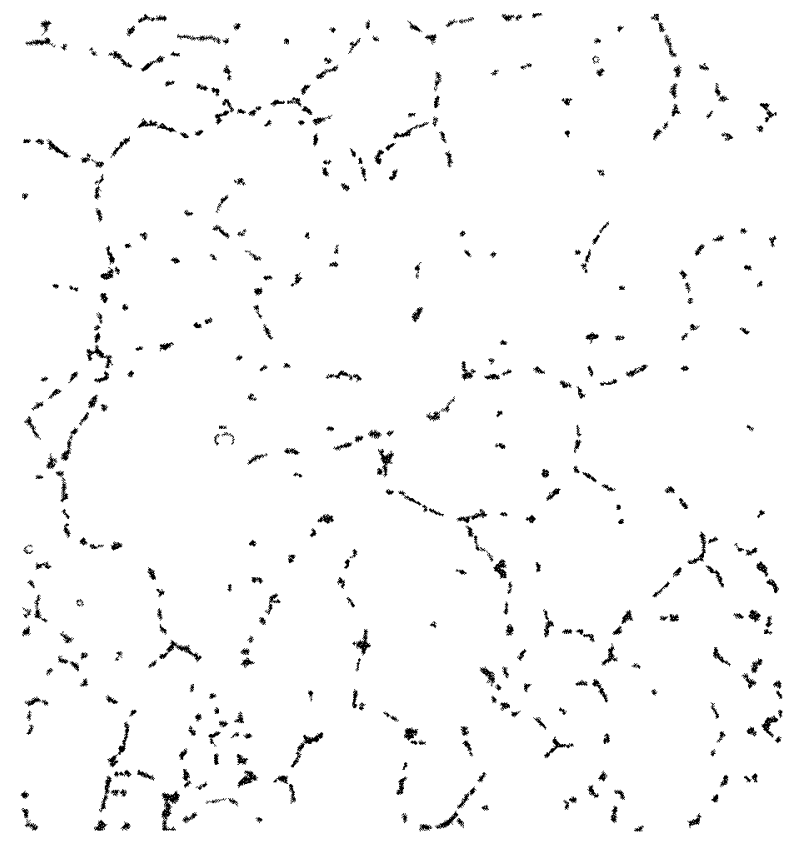

(a) As-received

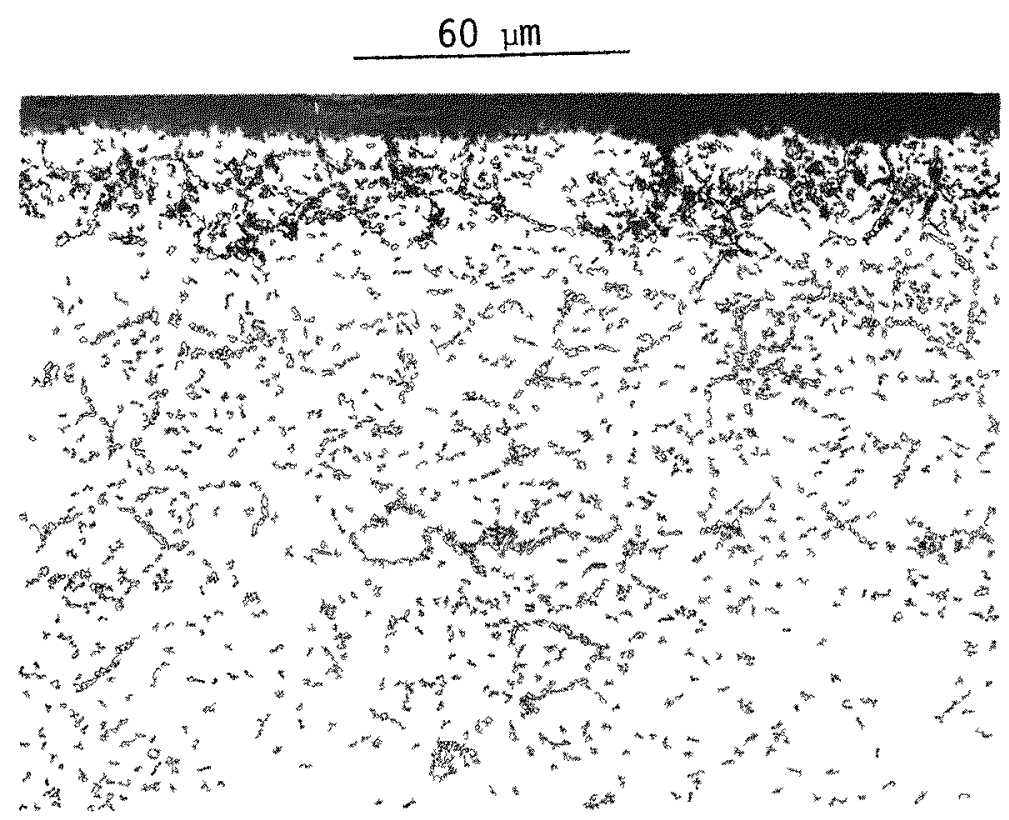

(b) Sodium-exposed (2000 hours)

FIGURE 21. Optical Micrographs of As-received and Sodium-exposed M-813. 
The austenite matrix shows extensive second phase precipitation. The sigma phase precipitate size is much finer when compared with that of sodiumexposed AISI 310. This can be very easily explained on the basis that AISI 310 was cold-worked prior to sodium exposure. The cold-work facilitated enhanced nucleation of sigma and subsequent growth during the early stages of exposure. Although the precipitate particles in M-813 were not identified to be sigma, the characteristic island appearance, the high electron vacancy parameter, and the extremely favorable composition are fairly conclusive that they are sigma phase precipitates. The sodium attack in M-813 reached a maximum depth of approximately $25 \mu \mathrm{m}$ from the surface.

The EPMA data of sodium-exposed M-813 are given in Figures 22 and 23. As expected, there is depletion of $\mathrm{Ni}, \mathrm{Ti}, \mathrm{Al}$ and $\mathrm{Cr}$ near the surface and an associated enrichment of $\mathrm{Fe}$ and Mo. The depleted zone seems to be about $5 \mu \mathrm{m}$. Due to the fairly high density of the precipitates, the profiles display several peaks within the material underneath the depleted zone.

The SEM photographs of the corroded surface of $M-813$ are given in Figure 24. The X-ray analysis of the surface indicates depletion of $\mathrm{Ni}, \mathrm{Cr}$ and $\mathrm{Ti}$, which is in excellent agreement with the EPMA data described above. It is also apparent from Figure 24 that the surface is masked by a layer of discrete micron-size nodes. These nodes are again enriched in $\mathrm{Fe}$ and $\mathrm{Mo}$ as in the case of AISI 316 and Nimonic PE16. Due to the higher concentration of Mo (4 wt\%) in M-813, the number density of these nodes is larger than for Nimonic PE16 (3.3 wt\% Mo).

\section{H. Inconel 718}

Incone 718 gets its high temperature strength from the precipitation of $\gamma^{\prime}$ and $\gamma^{\prime \prime}$. The recommended heat treatment promoted the formation of the two strengthening phases in the as-received alloy. $\gamma$ " usually precipitates around the grain boundaries as platelets or rods. 


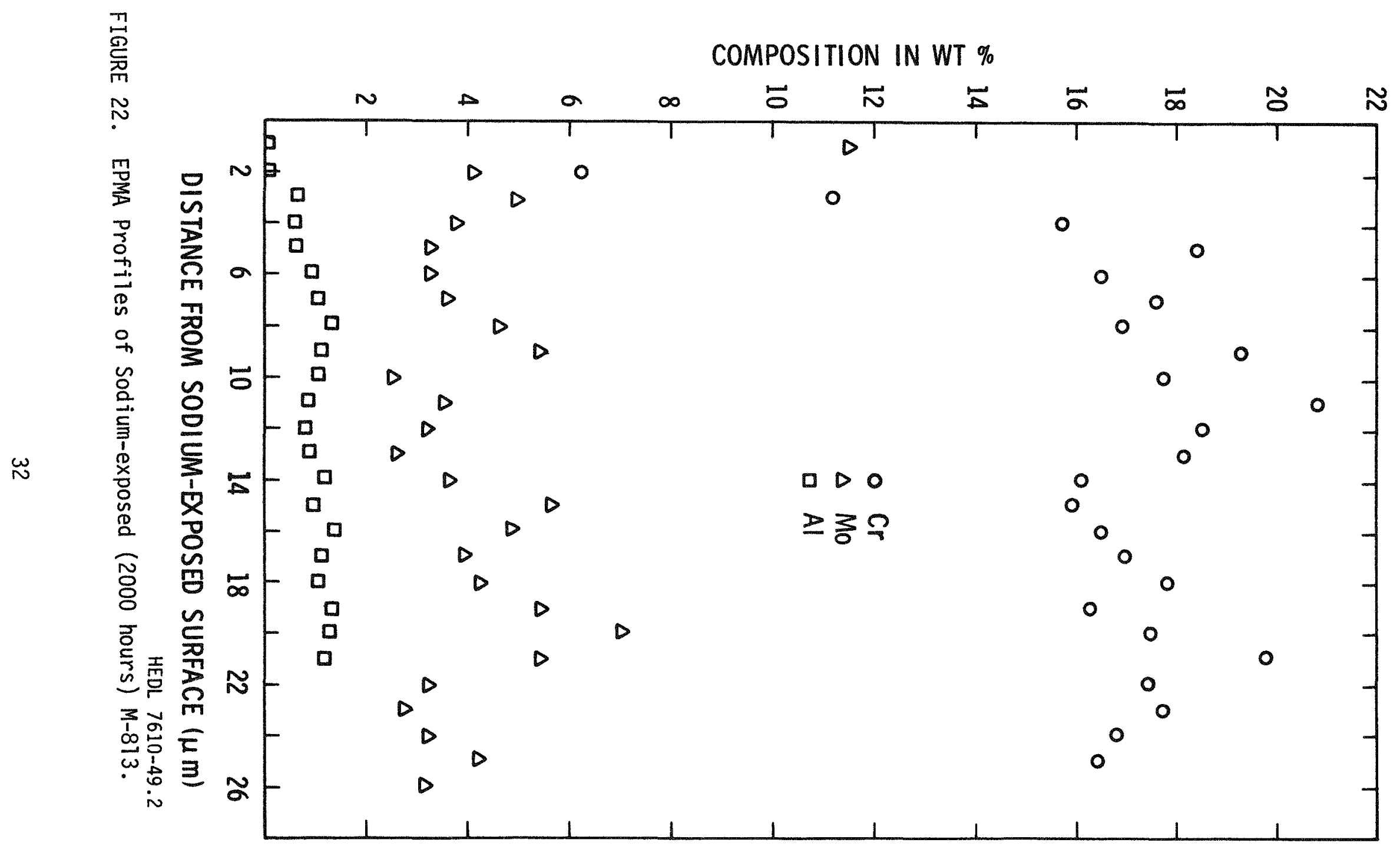




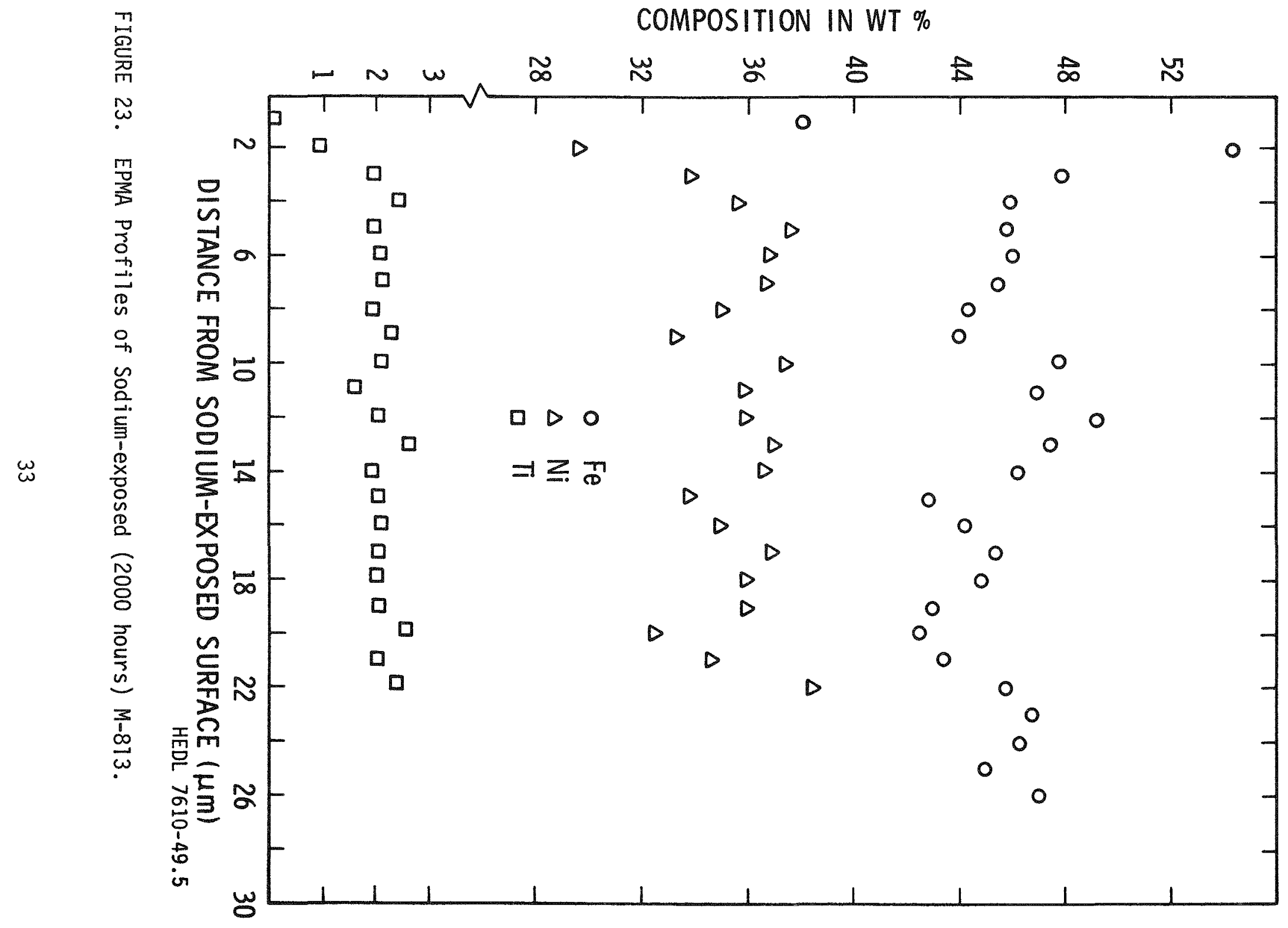




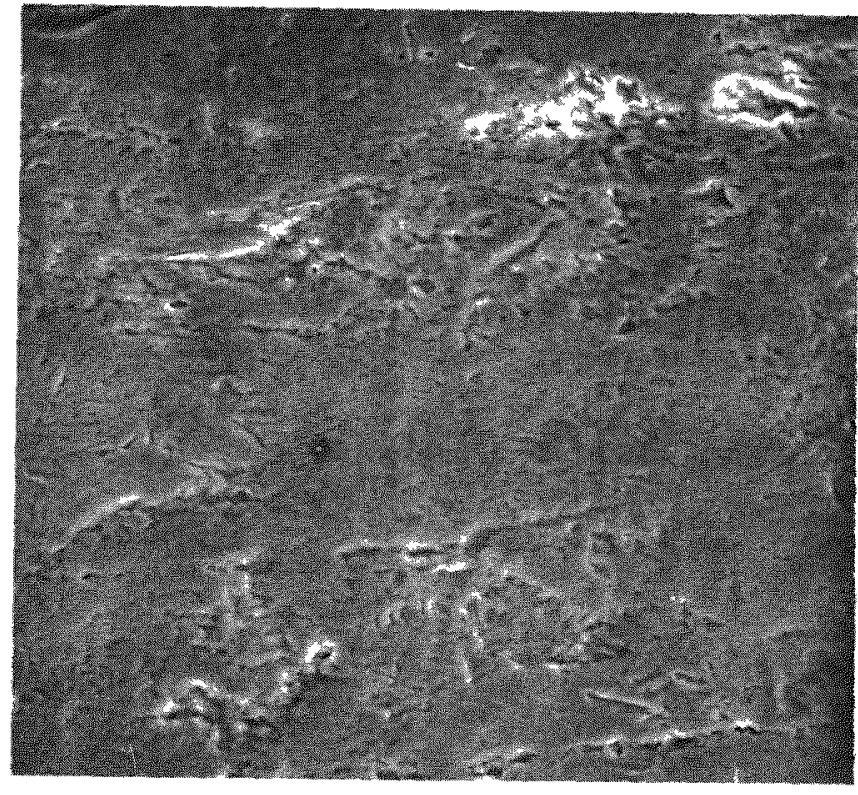

(a) As-received

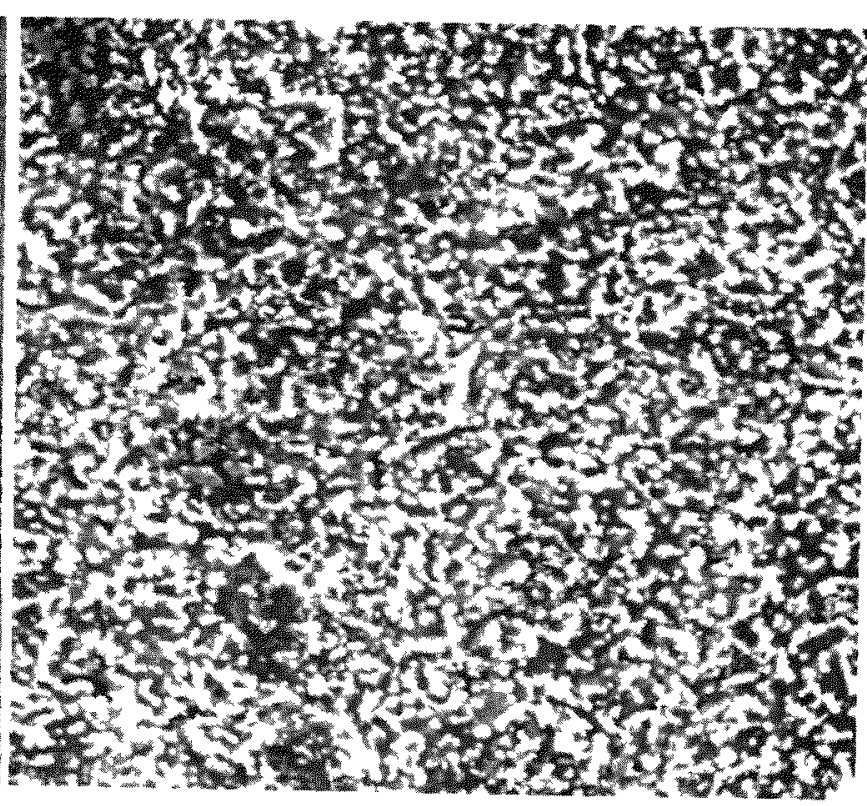

(b) Sodium-exposed
Relative $X$-ray Intensities: Fe- 1.0 $\mathrm{Cr}-.703 ; \mathrm{Ni}-.564 ; \mathrm{MO}-.059 ; \mathrm{Ti}-.129$
Relative $X$-ray Intensities:

$\mathrm{Fe}-1.0 ; \mathrm{Cr}-.242 ; \mathrm{Ni}-.097 ; \mathrm{Mo}-.064$

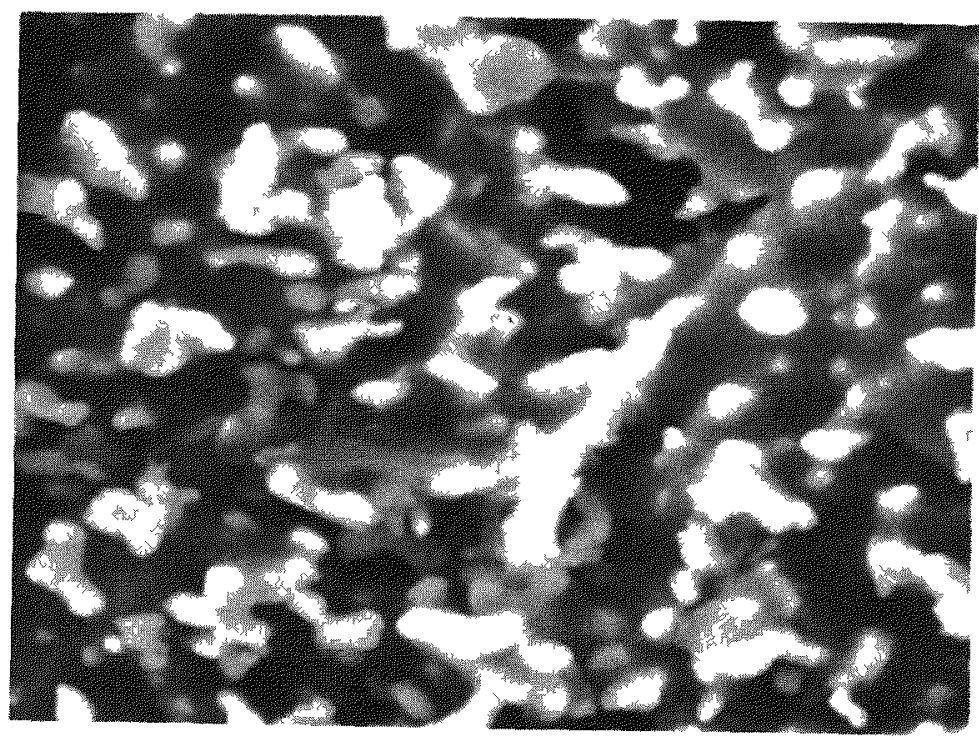

\section{(c) Sodium-exposed}

Relative X-ray Intensities: Node - Fe-1.000; Cr-.203; Ni-.04; Mo-.54

Matrix - Fe-1.000; $\mathrm{Cr}-.337 ; \mathrm{Ni}-.262 ; \mathrm{Ti}-.025$

FIGURE 24. SEM Photographs of As-received and Sodium-exposed (2000 hours) M-813. 
Photographs of sodium-exposed Incone 718 are shown in Figure 25. This alloy showed the heaviest material loss among the precipitation strengthened alloys. The sodium attack appears to have been initiated by intergranular penetration and progressed to a depth of approximately $40 \mu \mathrm{m}$. The major stengthening phase, which is $\gamma^{\prime \prime}\left(\mathrm{Ni}_{3} \mathrm{Nb}\right)$, is expected to eventually transform to overaged $\delta$ after long-term operation at $700^{\circ} \mathrm{C}$, leading to a loss in strength.

The surface characterization of Incone 718 by SEM is illustrated in Figure 26. The X-ray analys is of as-received and sodium-exposed samples indicate a drastic depletion of $\mathrm{Ni}$ and $\mathrm{Cr}$ and also depletion of $\mathrm{AT}$ and $\mathrm{Ti}$. Molybdenum-enriched micron-size nodes typical of AISI 316, Nimonic PE16, and $M-813$ are also seen on the surface. The EPMA data obtained from sodium exposed Inconel 718 are in excellent agreement with the SEM data, indicating depletion of $\mathrm{Ni}, \mathrm{Cr}$ and $\mathrm{Ti}$ and an enrichment of iron.

\section{DISCUSSION}

As mentioned in Section I, the tests on the same commercial alloys were performed at HEDL and WR\&D under almost identical experimental conditions, with a view to check the reproducibility of the data. The results mentioned above are in excellent agreement with those obtained at WR\&D. The tests not only confirmed the reproducibility of such tests in different loops, but also yielded very important and useful information about the nature of sodium corrosion of commercial alloys. Since the exposure time for the alloys was limited to 2000 hours, the extent of subsurface damage like porosity and intergranular attack (IGA) is not immediately apparent for many of the alloys. Therefore, the sodium corrosion behavior of many of the alloys cannot be extrapolated to longer exposure times, with respect to porosity and IGA.

Sigma phase formation due to $700^{\circ} \mathrm{C}$ sodium exposure was seen in the reference material and AISI 310. The two materials have fairly high chromium content which favors the precipitation of sigma. In addition, both these 


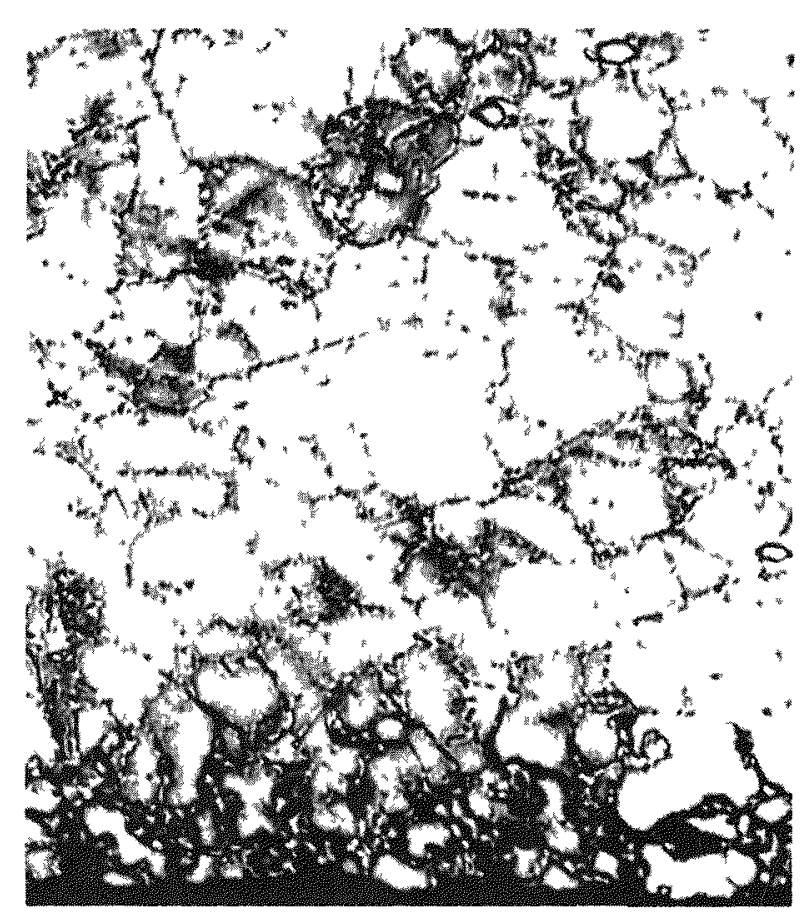

$60 \mu \mathrm{m}$

FIGURE 25. Optical Micrograph of Sodium-exposed (2000 hours) Inconel 718. 


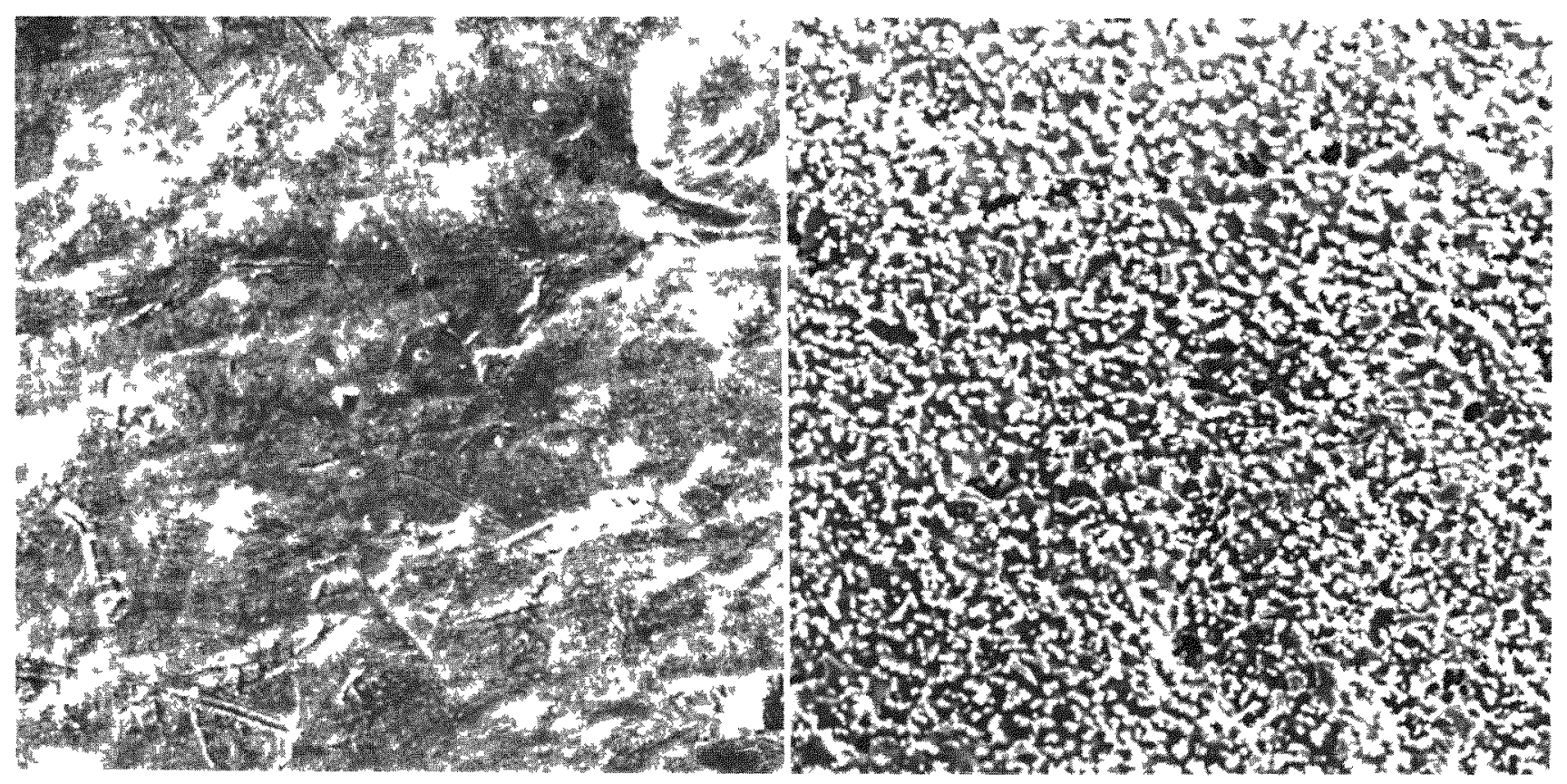

(a) As-received

(b) Sodium-exposed (500 hours)

Relative X-ray Intensities: Fe-1.0; $\mathrm{Ni}-2.05 ; \mathrm{Mo}-.25 ; \mathrm{Ti}-.21 ; \mathrm{Al}-.24 ; \mathrm{Cr}-1.61 \quad \mathrm{Cr}-.92 ; \mathrm{Ni}-1.0 ; \mathrm{Mo}-.27 ; \mathrm{Ti}-.12 ; \mathrm{Al}-.11$ $30 \mu \mathrm{m}$

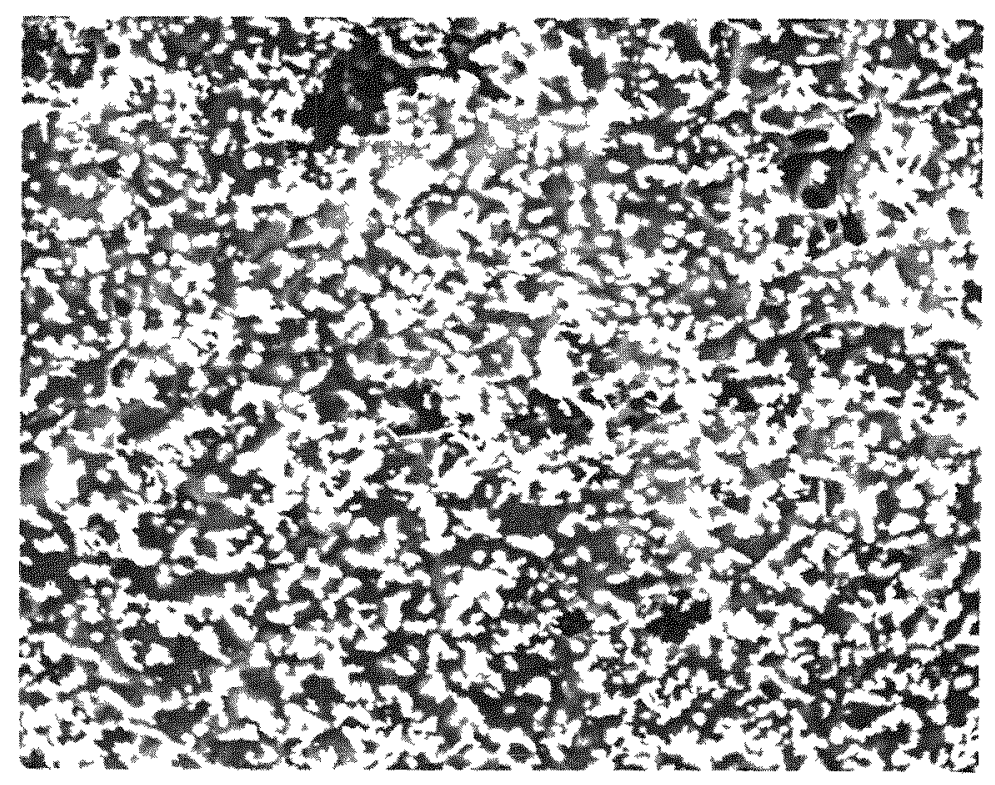

(c) Sodium-exposed (2000 hours)

Relative X-ray Intensities: Area Scan--Fe-1.0; $\mathrm{Cr}-.47 ; \mathrm{Ni}-.5 ; \mathrm{Mo}-.29 ; \mathrm{Ti}-.06 ; \mathrm{Al}-.05$ Node--Fe-1.0; $\mathrm{Cr}-.36 ; \mathrm{Ni}-.16 ; \mathrm{Mo}-.96 ; \mathrm{A} 7-.04$ Matrix--Fe-1.0; $\mathrm{Cr}-.43 ; \mathrm{Ni}-.46 ; \mathrm{Mo}-.07 ; \mathrm{AT}-.05$

FIGURE 26. SEM Photographs of As-received and Sodium-exposed Inconel 718. 
materials are cold worked, and cold work prior to aging has been known ${ }^{(3)}$ to accelerate the precipitation of intermetallic phases. In the reference material Mo (2.5 wt\%) is also present, which enhances the sigma forming tendency more than that with $\mathrm{Cr}$. Since carbon does not have much solubility in sigma, the low carbon level in AISI 310 promoted the formation of large quantities of sigma in the material. The absence of sigma phase precipitation in alloy 330 is not surprising. As pointed out by Barrows and Newkirk, (7) the critical electron vacancy number for sigma formation is increased by nickel atoms replacing the iron atoms. This is perhaps the same reason for the lack of sigma forming tendency in the precipitationhardened alloys.

All the sodium-exposed commercial alloys experienced depletion of alloying elements near the exposed surface. Depletion of alloying elements Al, Ni, $\mathrm{Cr}, \mathrm{Mn}, \mathrm{Ti}, \mathrm{Si}$, and $\mathrm{Nb}$ was noted in general. Enrichment of iron at the corroded surface is a common feature to a 11 the alloys. Among the Mobearing alloys, only alloy A-286 (1.25 wt\% Mo) did not exhibit a surface enrichment of Mo. This indicates that there perhaps is a critical Mo concentration below which Mo-enrichment is not observed. Although the corroded surface shows enrichment of $\mathrm{Fe}$ and Mo, these elements are also continuously lost from the material. The enrichment is relative and is due to the nonstoichiometric release of the other alloying elements.

The surfaces of alloys (Inconel 718, AISI 316, M-813, PE16) enriched with Mo are covered with discrete micron-size nodes containing primarily $\mathrm{Fe}$ and Mo. Surface nodes similar to these have been observed previous $7 y^{(5)}$ in the 316 stainless steel. These nodes have been extracted from the corroded surface and analyzed by means of a SEM at WR\&D laboratories. The analysis indicated the nodes to conform to the Laves composition, $\mathrm{Fe}_{2} \mathrm{Mo}$. This is the same phase that Weiss and Stickler ${ }^{(3)}$ observed during the thermal aging of Type 316 stainless steel at $730^{\circ} \mathrm{C}$.

The number density of Mo-rich nodes appears to be decreasing with exposure time in Type 316 stainless stee1, whereas in alloys M-813, PE16 and 718 this 
phenomenon is not easily noticeable. It should be pointed out that the three precipitation-hardened alloys have Mo in excess of 3 wt\%, while Type 316 stainless steel contains 2.5 wt\% Mo. If this trend continues, one would expect the nodes to disappear from the sodium-exposed surface of Type 316 stainless steel after a long exposure time. It can be concluded from the above that the molybdenum enrichment and the micron-size node formation occur only in alloys containing Mo in excess of 1.25 wt\%.

The average depleted zone thickness of the sodium-exposed alloys is $5 \mu \mathrm{m}$. Only in the case of AISI 310 the depleted zone thickness is $20-25 \mu \mathrm{m}$. This feature of AISI 310, coupled with a high weight loss rate, makes the alloy unsuitable for fuel cladding applications at $700^{\circ} \mathrm{C}$.

Intergranular attack (IGA) has been observed in Nimonic PE16 and Inconel 718. The IGA depth is $25 \mu \mathrm{m}$ (Figure 17) in Nimonic PE16 and $30 \mu \mathrm{m}$ (Figure 25) in Inconel 718. IGA is not readily apparent in the remaining materials, except possibly M-813. IGA, in the form of material removal adjacent to grain boundaries, is evident in M-813, but it is not as widespread as in PE16 and 718. This situation might change with increasing exposure time resulting in a uniform attack in M-813, similar to PE16 and 718. The three materials PE16, 718 and M-813 have micron-size nodes and IGA tendencies (including M-813) and an additional common feature is a molybdenum content in excess of 2.5 wt\%. The possible increase in IGA depth with increasing exposure time is a cause for concern in these materials, since it increases the notchsensitivity of the materials. Inconel 718 with its pronounced IGA and a high weight loss rate is an unsuitable cladding alloy candidate at $700^{\circ} \mathrm{C}$. However, longer exposures are required for PE16 and M-813 to determine their applicability as a fuel cladding material at $700^{\circ} \mathrm{C}$.

Relative iron enrichment with a non-stoichiometric depletion of other alloying elements suggests that prolonged exposure of an alloy containing low Mo to $700^{\circ} \mathrm{C}$ sodium would change the composition of the surface layer to that of almost pure iron. 


\section{CONCLUSIONS}

Exposure to sodium at $700^{\circ} \mathrm{C}$ led to a general depletion at the surface of $\mathrm{Ni}, \mathrm{Cr}, \mathrm{Ti}, \mathrm{Si}, \mathrm{Mn}$ and $\mathrm{Nb}$, and enrichment of iron and also Mo if present at $>1.25$ wt\% composition. Iron enrichment at the surface is a common feature of all the sodium-exposed alloys and is verified by both SEM and EPMA Studies. The average depleted zone thickness is $5 \mu \mathrm{m}$, with the exception of AISI 310, which showed an unusually large thickness of $25 \mu \mathrm{m}$. This indicates that prolonged exposure of an alloy to $700^{\circ} \mathrm{C}$ sodium would ultimately result in the formation of an iron-rich (Ferrite) surface layer.

Three types of sodium-induced corrosion were observed, depending on the corrosion rate of the alloy. Inconel 706, with its low corrosion rate, displayed grain-orientation dependent striations on the surface. Due to increase in material loss, this feature was not clearly noticeable at longer exposure times. Although alloy A-286 has the lowest corrosion rate, grainorientation dependent striations were not seen. However, the surface structure is similar to that of Inconel 706 after 2000 hours. Alloys with intermediate corrosion rates (AISI 316, Nimonic PE16, M-813 and Inconel 718) containing $>1.25$ wt\% Mo, consist of micron-size nodes enriched with $\mathrm{Fe}$ and Mo. The data suggest that the appearance of these nodes perhaps persists for a long period of time in alloys containing $>2.5$ wt $\%$ Mo. The high corrosion rate a.lloys (AISI 310 and Alloy 330 ) exhibit scale-like formations and irregularly shaped holes, with the number of holes increasing with the corrosion rate of the alloy. 


\section{REFERENCES}

1. W. F. Brehm, L. E. Chulos, J. C. McGuire, A. C. Leaf and R. P. Colburn, "Techniques for Studying Corrosion and Deposition of Radioactive Materials in Sodium Loops," IWGFR/7 IAEA Specialists' Meeting, Dimitrovgrad, USSR, 1975.

2. S. A. Shiels, A. R. Keeton and R. P. Anantatmula, The In-Sodium Corrosion Behavior of Candidate Breeder Reactor Fuel Cladding and Duct A1loys, HEDL-TME 77-71, Hanford Engineering Development Laboratory, Richland, WA, February 1978.

3. B. Weiss and R. Stickler, "Intermediate Phases in the Mo-Fe-Co, Mo-Fe-Ni, and Mo-Ni-Co Ternary Systems," Met. Trans., Vo1. 3, p. 851, 1972.

4. D. K. Das, S. P. Rideout and P. A. Beck, "Phase Instabilities During High Temperature Exposure of 316 Austenitic Stainless Stee1," Trans. AIME, Vo1. 194, p. 1071, 1952.

5. E. Berkey and G. A. Whitlow, "Microstructural and Compositional Changes in Sodium-Exposed Stainless Steel by Scanning Electron Microscopy," Chemical Aspects of Corrosion and Mass Transfer in Liquid Sodium, Proceedings of Symposium of the Metallurgical Society of AIME, "ed. S. A. Jansson, Detroit, MI, p. 65, October 19 \& 20, 1971.

6. C. Bagnall and R. E. Witkowski, The Influence of Thermal Aging and Sodium Corrosion on the Microstructural Stability of AISI Type 310 "S" and A110y 330 at $700^{\circ} \mathrm{C}$, WARD-NA-3045-47, Westinghouse Advanced Reactors Division, 1978.

7. R. G. Barrows and J. B. Newkirk, "A Modified System for Predicting $\sigma$ Formation," Met. Trans., Vo1. 3, p. 2889, 1972. 


\section{DISTRIBUTION}

$\underline{U C-79}$ (240)

$\underline{U C-79 b}$ (38)

DOE/RL (1)

Chief Patent Attorney

DOE/FFTFPO

(5)

Director

DOE/RRT-HQ

Ass istant Director, Materials Technology

Chief, Fuel Systems Branch

Chief, Materials and Chemistry Branch

HEDL (43)

\begin{tabular}{|c|c|}
\hline $\begin{array}{l}\text { R.P. Anantatmula (2) } \\
\text { J.M. Atwood } \\
\text { E.O. Badgett } \\
\text { T.K. Bierlein } \\
\text { W.F. Brehm (2) } \\
\text { R.J. Cash } \\
\text { L.E. Chulos } \\
\text { T.T. Claudson } \\
\text { R.P. Colburn } \\
\text { C.M. Cox } \\
\text { E.A. Evans } \\
\text { J.J. Ho Imes } \\
\text { M.K. Korenko } \\
\text { J.J. Laidler } \\
\text { J.M. Lutton }\end{array}$ & $\begin{array}{l}\text { W/C-51 } \\
\text { W/C-45 } \\
\text { W/C-51 } \\
\text { W/A-57 } \\
\text { W/C-51 } \\
\text { W/A-11 } \\
\text { W/C-51 } \\
\text { W/C-15 } \\
\text { W/C-51 } \\
\text { W/E-5 } \\
\text { W/JAD } \\
\text { W/A-58 } \\
\text { W/A-57 } \\
\text { W/A-57 } \\
\text { W/C-51 }\end{array}$ \\
\hline
\end{tabular}

H.P. Maffei

J.J. McCown

J.C. McGuire

L.D. Muhlestein

L.L. Nachtmann

M.M. Paxton

R.R. Rake

W.E. Roake

W.F. Sheely

J.L. Straalsund

J.D. Watrous

G.L. Wire

E.R. Wood

H.H. Yoshikawa

Central Files

Pub 1 Services
$W / C-51$

$W / C-53$

W/C -51

$W / 221 T$

$W / C-51$

W/A-58

$W / C-51$

$W / E-2$

$W / C-44$

W/A-58

W/A-105

W/A-53

$W / C-51$

W/A-62

(10) $W / C-110$

(2) $\mathrm{W} / \mathrm{C}-115$ 